\title{
Numerical investigation of single bubble dynamics in liquid sodium pool
}

\author{
ARJUN PRADEEP*(D) and ANIL KUMAR SHARMA \\ Indira Gandhi Centre for Atomic Research, HBNI, Kalpakkam 603102, India \\ e-mail: arjun@igcar.gov.in; aksharma@igcar.gov.in
}

MS received 20 March 2018; revised 3 August 2018; accepted 22 October 2018; published online 9 February 2019

\begin{abstract}
The single gas bubble rise dynamics in liquid sodium/sodium-potassium alloy (NaK) pool due to entrainment of argon cover gas/non-condensable fission gas (xenon) have received considerable attention in the safe operation of Sodium-cooled Fast Reactor (SFR). Numerical simulation of single bubble dynamics in liquid sodium/ $\mathrm{NaK}$ pool is an essential intermediate step for the evaluation of rise velocity and shape changes, which are of utmost importance in areas of reactor safety concerned with source term evaluation and cover gas purification. The interFoam solver of OpenFOAM package is used to evaluate inert gas bubble rise dynamics in stagnant liquid metal pool of sodium and $\mathrm{NaK}$. The governing equations are discretized and solved using the Volume of Fluid (VOF) based solver available in OpenFOAM with appropriate initial and boundary conditions. The VOF module of the solver is validated against numerical benchmark data and experimental results available in literature. The bubble dynamics in liquid sodium/ $\mathrm{NaK}$ pool are studied in terms of trajectory, shape and rise velocity for diameters ranging from 10 to $20 \mathrm{~mm}$, domain aspect ratios and for different gas-liquid systems. The study shows that the bubble rise velocity increases with diameter for liquid sodium systems. The rise behavior of single inert gas bubble in liquid water and sodium pool are compared. The study supports the use of air-water system as a simulant for studying bubble dynamics in liquid sodium systems as suggested by other researchers. The study is very useful and forms an intermediate step towards the development of an OpenFOAM based computational framework to analyze heat and mass transfer from single bubble rising in liquid sodium pool for reactor safety studies.
\end{abstract}

Keywords. Bubble rise velocity; sodium; OpenFOAM.

\section{Introduction}

In Sodium-cooled Fast Reactors (SFRs), bubbles can result from entrainment of argon cover gas and non-condensable fission gas (xenon) within the sodium/sodium-potassium alloy $(\mathrm{NaK})$ pool and also from sodium boiling following a flow/power transient [1]. The areas of reactor safety concerned with radioactive source term evaluation due to xenon bubble transport in sodium pool [2] and argon cover gas purification in sodium/ $\mathrm{NaK}$ bubbler [3] is highly dependent on the bubble dynamic parameters such as rise velocity, shape and path. The rise velocity is an important parameter which limits the heat and mass transfer phenomena from rising bubbles in liquid sodium pool of SFR. One very fundamental study to be carried out towards this understanding is the rising and deforming of a single inert gas bubble in stagnant sodium/ $\mathrm{NaK}$ pool. The single bubble dynamics in liquid pool is a function of bubble physical characteristics, properties of gas-liquid system and operating conditions. The knowledge of single bubble rise

*For correspondence dynamics forms an intermediate step towards the evaluation of complex heat and mass transport phenomena associated with SFR safety.

Numerous experiments [4] have been carried out to understand single air bubble dynamics in transparent liquids, especially water. Experimentally single gas bubbles can be generated using low gas injection rates. Experimental studies on bubble dynamics in transparent systems are measured using optical methods, often an imaging technique with a high speed camera. However, limitations in measurement techniques for opaque liquids reduced the bubble dynamic experiment capabilities in liquid metals (e.g., liquid sodium, NaK). The measurement techniques used for gas-liquid metal flows can be classified as invasive techniques (use of electrical resistivity, electrical capacitance, optical fiber, acoustic probes) or non-invasive techniques such as soft field tomography (use of acoustic, ultrasonic, electrical or magnetic signals) and hard field tomography (use of X-rays, neutron beams and gammarays). The $\mathrm{X}$-ray attenuation techniques have been employed to view deep into the non-transparent liquid metal systems of GaInSn, iron and steel [5-7]. 
The development of Computational Fluid Dynamics (CFD) technology has provided a convenient, effective and inexpensive tool to study bubble dynamics. This represents a complement to experimental measurements and provides better physical understanding of the phenomenon. Several numerical studies have been carried out to date to understand single bubble rise dynamics in stagnant liquids [8-15]. In source term evaluation studies related to SFR, single bubble dynamics in sodium pool is typically studied for a bubble size range from $10 \mathrm{~mm}$ to $30 \mathrm{~mm}[2,16,17]$ based on the maximum stable bubble size evaluated from fluid properties. However, based on experimental observations the bubble size is between $11 \mathrm{~mm}$ and $23 \mathrm{~mm}$ for SFR source term studies [18]. The fluid properties and experimental observations from earlier studies suggest a typical bubble size of $20 \mathrm{~mm}$ for SFR studies. Until now, theoretical research of the single bubble dynamics in liquid sodium pool were studied using correlations available in literature for bubble terminal velocity [19] or solving the equation of motion in terms of inertia, buoyancy and drag force [16].

In the present study, interFoam solver of Open Field Operation and Manipulation (OpenFOAM) is used to investigate the rise dynamics of single inert gas bubble in liquid sodium/ $\mathrm{NaK}$ pool. The interFoam module used in the present study is verified and validated with numerical benchmarks and experimental correlations available in literature respectively for single bubble dynamics. Grid independence study is carried out to find the appropriate mesh size required for simulating inert bubble rise in liquid sodium. The bubble dynamics in liquid sodium is studied for various domain Aspect Ratio $(A R=H e i g h t /$ Width $)$, fluids and range of bubble diameters to understand their influence on bubble behavior. The present study is an intermediate step towards development of an OpenFOAM based computational framework to analyze heat and mass transfer from single bubble rising in liquid sodium pool for reactor safety studies.

\section{Physical description of problem}

The numerical investigation of single bubble (fluid 2) dynamics in liquid sodium (fluid 1) pool is carried out in a rectangular domain as shown in figure 1. Initially, the spherical bubble of diameter $d_{B}$ is positioned at an elevation of $0.5 d_{B}$ from the bottom wall, along the central vertical axis. The gravitational acceleration of $9.81 \mathrm{~m} / \mathrm{s}^{2}$ is considered for the study. The present study considers thermal equilibrium between the gas bubble and liquid pool. The different parameters that affect the bubble dynamics are bubble diameter, domain Aspect Ratio $(A R=$ Height/Width $)$ and fluids. Hence the present study focuses on parametric studies to evaluate their influence.

\section{Computational method}

The rise of an inert gas bubble in liquid sodium pool is numerically investigated using the interFoam [20] solver available in an open source CFD package, OpenFOAM [21] version 3.0.0.

\subsection{Governing equations}

The governing conservation equations for mass, momentum and phase fraction are given below.

Continuity equation

$$
\nabla \cdot \vec{u}=0
$$

where, the mixed velocity is given by,

$$
\vec{u}=\alpha_{1} \vec{u}_{1}+\left(1-\alpha_{1}\right) \vec{u}_{2}
$$

The volume fraction of fluid 1

$$
\alpha_{1}=\left\{\begin{array}{l}
1 \quad \text { in fluid } 1 \\
0 \quad \text { in fluid } 2 \\
0<\alpha_{1}<1 \text { at the interface }
\end{array}\right.
$$

Momentum equation

$$
\begin{aligned}
\frac{\partial(\rho \vec{u})}{\partial t}+\nabla \cdot(\rho \vec{u} \vec{u})= & -\nabla p_{r g h}+\nabla \cdot\left[\mu\left(\nabla \vec{u}+(\nabla \vec{u})^{\mathrm{T}}\right)\right] \\
& -\vec{g} \cdot \vec{x} \nabla \rho+\sigma \kappa \nabla \alpha_{1}
\end{aligned}
$$

where, $p_{r g h}$ is pseudo hydrostatic (dynamic) pressure, $\vec{x}$ is position vector, $\vec{g}$ is gravitational acceleration and $\sigma$ is surface tension. The transport properties of mixed fluid, density $\rho$ and viscosity $\mu$ are evaluated from the volume fraction weighted transport properties of two fluids.

$$
\begin{gathered}
\rho=\alpha_{1} \rho_{1}+\left(1-\alpha_{1}\right) \rho_{2} \\
\mu=\alpha_{1} \mu_{1}+\left(1-\alpha_{1}\right) \mu_{2} \\
p_{r g h}=p-\rho \vec{g} \cdot \vec{x}
\end{gathered}
$$

Volume fraction equation for phase 1 [11]

$$
\frac{\partial \alpha_{1}}{\partial t}+\nabla \cdot\left(\vec{u} \alpha_{1}\right)+\nabla \cdot\left[\vec{u}_{r} \alpha_{1}\left(1-\alpha_{1}\right)\right]=0
$$

where, the relative velocity between phases 1 and 2 is

$$
\vec{u}_{r}=\vec{u}_{1}-\vec{u}_{2}
$$

curvature of the interface is given by,

$$
\kappa=-\nabla \cdot \hat{n}=-\nabla \cdot\left(\frac{\nabla \alpha_{1}}{\left|\nabla \alpha_{1}\right|}\right)
$$

where, $\hat{n}$ is the interface unit normal vector 


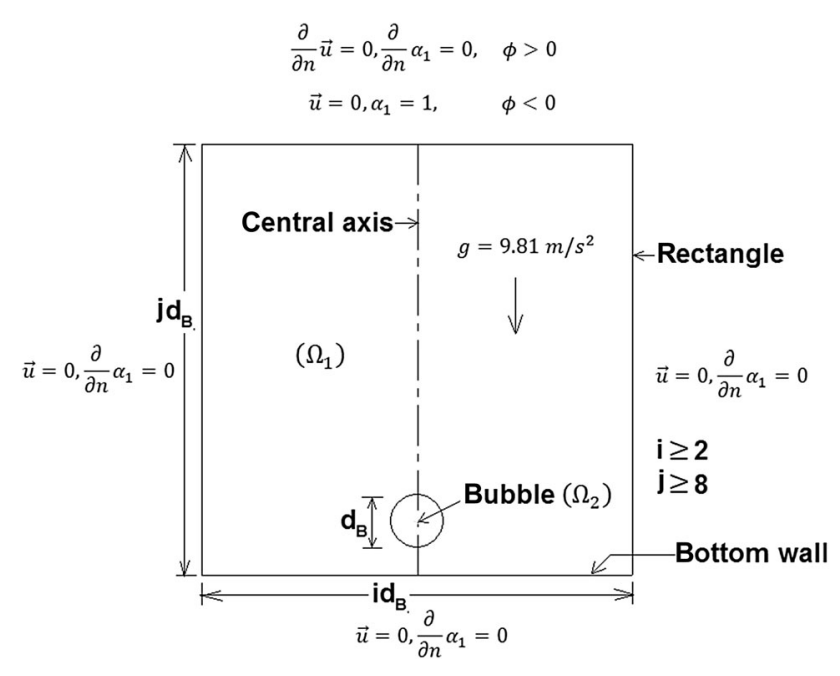

Figure 1. Computational domain.

\subsection{Boundary conditions}

The bottom and side walls are assigned no-slip boundary condition. The velocity is set to zero, the gradient of volume fraction of fluid 1 in the direction normal to wall boundary is also set to zero. The gradient of pressure normal to the wall boundary is calculated based on the velocity boundary condition predicted boundary flux $(\phi)$. The top boundary is free to the atmosphere and permits both inflow and outflow. Hence, a mixed boundary condition is used for the top boundary. The gradient of fluid 1 volume fraction in the direction normal to the top boundary is set to zero for outflow and for inflow, fluid 1 volume fraction is unity. The gradient of velocity in the direction normal to the top boundary is set to zero for outflow $(\phi>0)$ and velocity is set to zero for inflow $(\phi<0)$. The static pressure at the top boundary is obtained by subtracting the dynamic pressure from the specified total pressure.

\subsection{Solution method}

The interFoam solver uses Volume of Fluid (VOF) method [22] with surface compression [23] approach to solve the governing conservation equations. The details of the logic used for solving, algorithm of interFoam solver and discretization of governing equations have been described in detail by Klostermann et al [11].

3.3a Discretization details: Spatial discretization is carried out using finite volume Gaussian integration method and the implicit Euler method is used for temporal discretization. The interpolation scheme used for convective term in the momentum equation is limited linear. The interpolation scheme used for first and second convective terms in phase fraction equation are van Leer scheme [24] and a specialized interface compression scheme to gain smoother interfaces. Multi-dimensional Universal Limiter for Explicit Solution (MULES) method is used to maintain boundedness of the volume fraction for solving volume fraction transport equation [21].

3.3b Solution algorithm: The algorithm used for pressure velocity coupling is PIMPLE (merged Pressure Implicit with Splitting of Operator (PISO) and Semi Implicit Method for Pressure Linked Equations (SIMPLE) algorithm) with three correction steps for pressure and two subcycles for the correction of the interface [21]. The PIMPLE algorithm has two loops, inner and outer [25]. In the outer loop all equations are solved while in the inner loop only continuity equation is solved. The pressure equation is solved in the outer loop for three correction steps to get time accuracy. The number of loops over the fluid 1 volume fraction is one for transient flow and the number of subcycles fluid 1 volume fraction is calculated is two. Conservative compression is used for compression term in the volume fraction equation. The equations solved are the pressure correction, the first pressure loop, the second and last pressure loops and the velocity equation. The solvers used are Preconditioned Bi-Conjugate Gradient (PBiCG) with Diagonal Incomplete-Lower Upper (DILU) preconditioner for velocity equation containing asymmetric matrices and the diagonal incomplete Cholesky (DIC) preconditioned CG for the pressure [21] equations containing symmetric matrices.

3.3c Computational details: The machine used for computation is Intel Core 2 Duo @ $2.4 \mathrm{GHz}$ and 4 GB of RAM running on Ubuntu 14.04 OS. The typical computational time for a $20 \mathrm{~mm}$ argon bubble rising in a rectangular domain of liquid sodium is 4 days for a grid size of $544 \times 544$.

\subsection{Post processing}

The post processing is carried out using the Swiss Army Knife for Foam (swak4Foam) toolbox. The toolbox allows user to put some conditions on the data extracted and also specify expressions involving the fields. The parameters evaluated using swak4Foam in the present study are the center of mass position coordinates of the bubble and the bubble rise velocity in $y$ direction [26]. The center of mass position coordinates of the bubble is evaluated using the following equation.

$$
\vec{X}_{c}=\int_{\Omega_{1} \cap \Omega_{2}} \frac{\alpha_{1} \vec{x}_{c} d A}{\alpha_{1} d A}
$$

where $\vec{x}_{c}=\left(x_{c}, y_{c}\right)$ is the center of mass position of an individual cell in the computational mesh. The average bubble rise velocity is obtained from ratio of axial displacement of center of mass to the rise time at any instant. 
The bubble rise velocity in $y$ direction is given as:

$$
U_{y}=\int_{\Omega_{1}} \frac{\alpha_{1} u_{y} d A}{\alpha_{1} d A}
$$

Where $u_{y}$ is the velocity in $y$-direction in an individual cell of the computational mesh. The terminal rise velocity is obtained by averaging the values of rise velocity which does not change with time [26].

\section{Validation}

The interFoam solver used in the present study is verified against numerical benchmark results for rising bubble case. The solver is also validated against experimental data available in literature. The details of numerical verification and experimental validation of solver is described in the following section.

\subsection{Numerical verification of solver}

The verification of VOF module of interFoam solver is carried out using numerical benchmark results available in literature [27] for single bubble dynamics. The domain considered for verification is a rectangular space of $2 \mathrm{~m}$ height and $1 \mathrm{~m}$ width, which is filled with fluid 1. A bubble containing fluid 2 is positioned in the domain at an elevation of $0.5 \mathrm{~m}$ above the bottom wall along the central axis. Numerical verification is carried out for $d_{B}=0.5 \mathrm{~m}$ using the fluid properties in each of the benchmark cases as shown in table 1 . The boundary conditions are no slip $(\vec{u}=0)$ for the top and bottom boundaries and slip for side boundaries. The gradient of volume fraction of fluid 1 in the direction normal to top, bottom and side boundaries are set to zero. The velocity is set to zero for top and bottom boundaries. The slip boundary conditions for the side wall sets the normal velocity component zero and the gradient of tangential velocity component in the normal direction as zero. The gradient of dynamic pressure in the direction normal to bottom and side boundaries are set to zero and constant pressure is set for the top boundary.

The quantitative benchmarks for bubble rise cases 1 and 2 were generated using numerical codes by Hysing et al [27]. The numerical codes used were TP2D, FreeLIFE and MooNMD. The TP2D code (Transport Phenomena in 2D) and FreeLIFE (Free-surface LIbrary of Finite Element) are

Table 1. Fluid properties for two benchmark validation cases.

\begin{tabular}{lcccccc}
\hline & $\begin{array}{c}\rho_{1}(\mathrm{~kg} / \\
\left.\mathrm{m}^{3}\right)\end{array}$ & $\begin{array}{c}\rho_{2}(\mathrm{~kg} / \\
\left.\mathrm{m}^{3}\right)\end{array}$ & $\begin{array}{c}\mu_{1} \\
(\text { Pa.s })\end{array}$ & $\begin{array}{c}\mu_{2} \\
(\text { Pa.s })\end{array}$ & $\begin{array}{c}\sigma(\mathrm{N} / \\
\mathrm{m})\end{array}$ & $\begin{array}{c}g(\mathrm{~m} / \\
\left.\mathrm{s}^{2}\right)\end{array}$ \\
\hline 1 & 1000 & 100 & 10 & 1 & 24.5 & 0.98 \\
2 & 1000 & 1 & 10 & 0.1 & 1.96 & 0.98 \\
\hline
\end{tabular}

based on finite element discretizations with level set method to track the location of the interface between two fluids. MooNMD (Mathematics and object-oriented Numerics in MagDeburg) is also based on finite element discretization and treats incompressible two phase flows using the arbitrary Lagrangian Eulerian approach. The grid sizes of TP2D and FreeLIFE numerical benchmarks were $h=1 / 320$ and $h=1 / 160$, respectively with corresponding time steps as $h / 16$ and $h / 2$. Štrubelj et al [11] uses an improved two fluid model with interface sharpened by conservative level set method. Klostermann et al [11] carried out numerical simulation for benchmark cases 1 and 2 using VOF approach implemented in OpenFOAM version 1.5.1. The grid size used by Klostermann et al [11] was $h=1 / 320$ with time step of $h / 2$.

Towards verification of the interFoam solver with present discretization schemes, the benchmark cases 1 and 2 are studied using four different mesh sizes, $h=1 / 40,1 / 80$, $1 / 160$ and $1 / 320$. The simulation time is $\mathrm{t}_{\text {final }}=3 \mathrm{~s}$ with a grid size dependent time step of $\Delta t=h / 16$ as shown in table 2. The computing times for both test cases are also presented in table 2 for better understanding of computing performance for the operating system used. The bubble profile for the benchmark case 2 at $t=3 \mathrm{~s}$ is predicted by the present study and is compared in figure 2 with the shapes calculated by earlier authors [27]. The shape is quite similar but from the visual qualitative comparison it is not possible to conclude the correctness of the solution. Hence, verification of the present study simulations is carried out for quantitative parameters such as bubble rise velocity and center of mass position.

Figure 3 shows the verification of temporal variation of rise velocity and center of mass position for benchmark cases 1 and 2 . The results of the VOF simulations for the four mesh sizes, $h=1 / 40,1 / 80,1 / 160$ and 1/320 are compared with the corresponding benchmark results predicted by the TP2D, FreeLIFE and MooNMD codes [28] and benchmarks of Hysing et al [27], Štrubelj et al [11] and Klostermann et al [11]. The verification of present study predicted results with earlier predictions in literature for benchmark case 1 is presented in table 3 . The percentage deviation of the present study for $h=1 / 320$ compared with the benchmark data [27] are around $1 \%$ for final position of center of mass at $t=3 \mathrm{~s}, 5 \%$ for incidence time of

Table 2. Grid refinement $1 / h$, number of elements, time step and computation time using present study for benchmark validation cases.

\begin{tabular}{lrccc}
\hline $1 / h$ & $n_{\text {elements }}$ & $\Delta t, \mathrm{~s}$ & $\begin{array}{c}\text { Computation } \\
\text { time case 1 }\end{array}$ & $\begin{array}{c}\text { Computation } \\
\text { time case 2 }\end{array}$ \\
\hline 40 & 3200 & $1.5 \times 10^{-3}$ & 3.5 minutes & 3.7 minutes \\
80 & 12800 & $7.8 \times 10^{-4}$ & 52 minutes & 1.7 hour \\
160 & 51200 & $3.9 \times 10^{-4}$ & 13.5 hour & 10.1 hour \\
320 & 204800 & $1.9 \times 10^{-4}$ & 13 days & 12 days \\
\hline
\end{tabular}



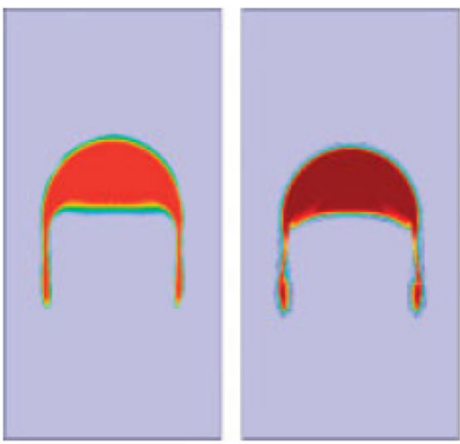

Comsol

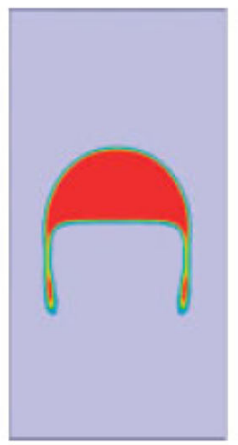

Fluent

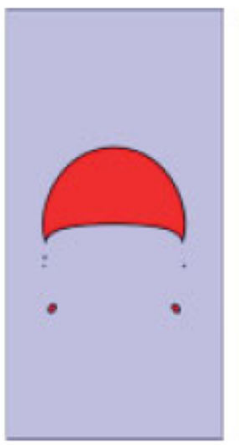

TP2D

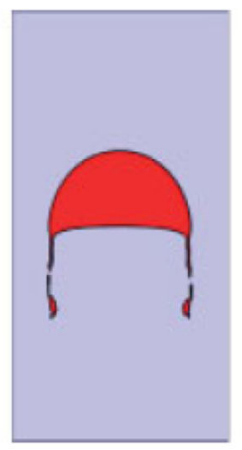

FreeLIFE

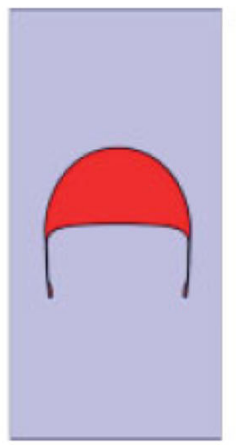

MooNMD

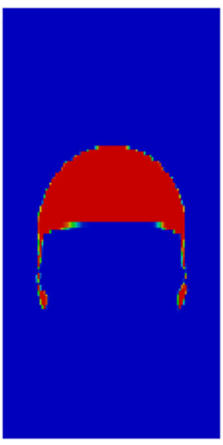

Present study

Figure 2. Verification of present study bubble profile with earlier predictions for benchmark case 2 at $t=3 \mathrm{~s}$.

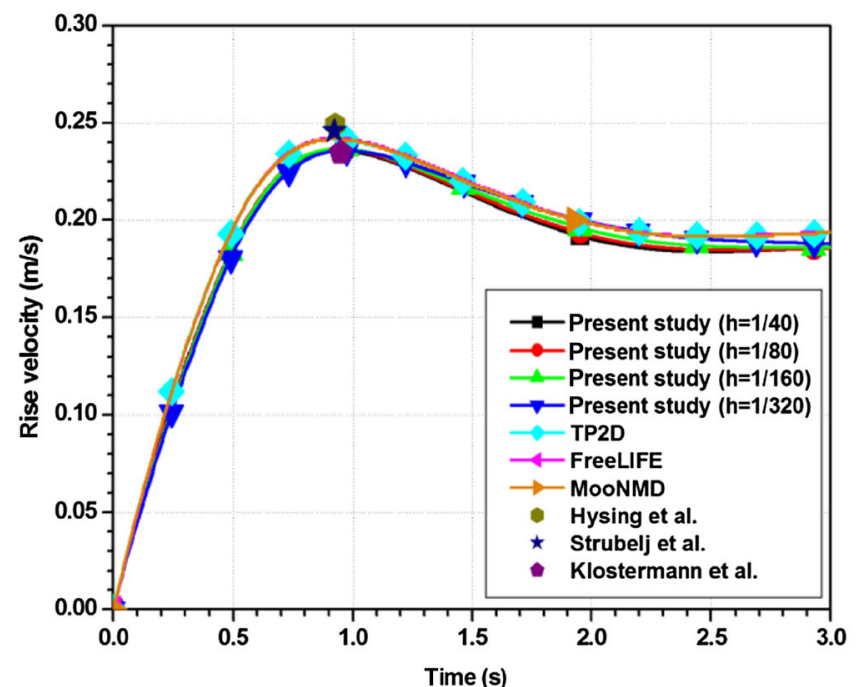

(a)

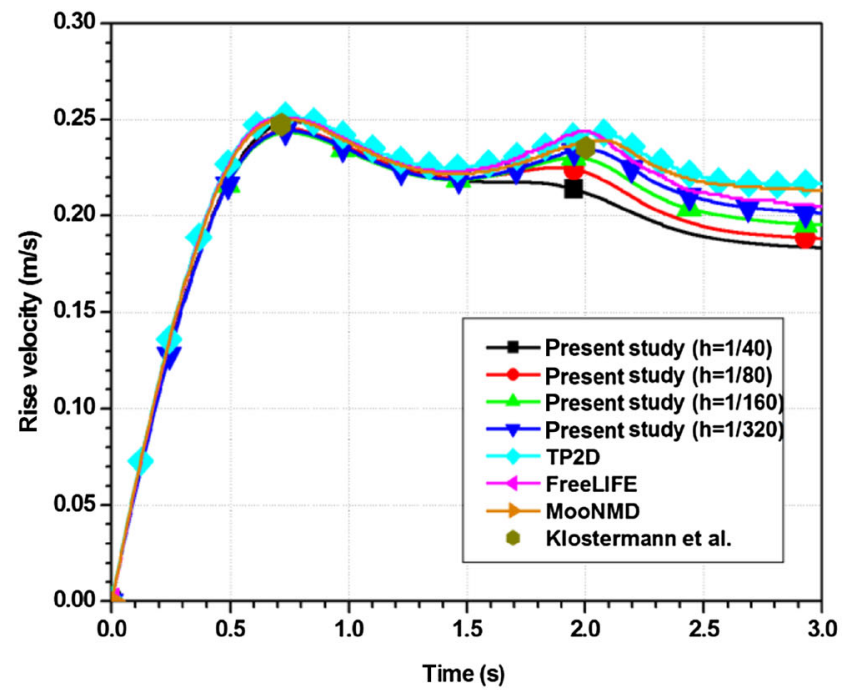

(c)

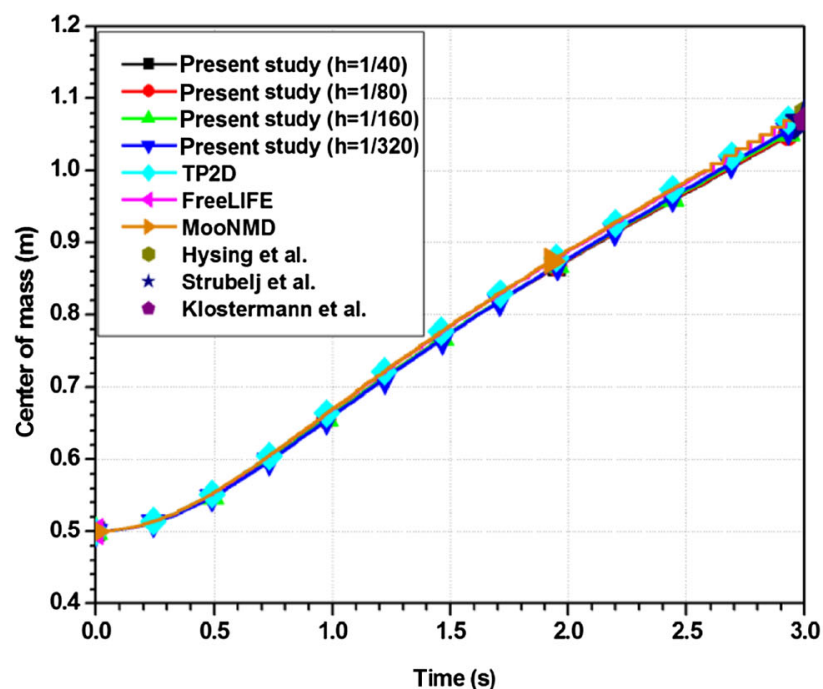

(b)

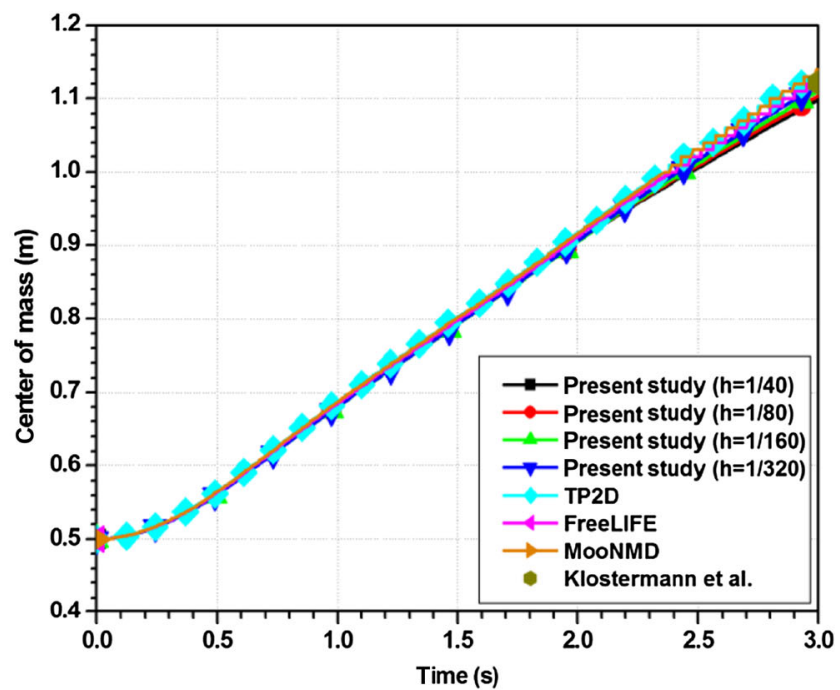

(d)

Figure 3. Verification of present study predicted center of mass position and rise velocity (top) case 1 (bottom) case 2. 
maximum velocity $\left(u_{\max }\right)$ and $3 \%$ for $u_{\max }$. However, the percentage deviation of the present study for $h=1 / 320$ compared with the OpenFOAM results of Klostermann et al [11] are around 1\% for all considered parameters for benchmark case 1 . For benchmark case 1 with high surface tension, the grid independence is not observed with increase in mesh refinement but the predictions are in close range of the benchmark results.

For benchmark case 2 with lower surface tension, increase in mesh refinement, resulted in predictions close enough to benchmark results of FreeLIFE code as shown in figure 3 and table 4 . The percentage deviation of the present study for $h=1 / 320$ compared with the benchmark data of FreeLIFE [28] are around 1\% for final position of center of mass at $t=3 \mathrm{~s}$ and incidence time of second maximum velocity $\left(u_{\max 2}\right), 3 \%$ for incidence time of first maximum velocity $\left(u_{\max 1}\right)$ and $u_{\max 1}$ and $4 \%$ for $u_{\max 2}$. However, the percentage deviation of the present study for $h=1 / 320$ as compared to the OpenFOAM results of Klostermann et al [11] are around $1 \%$ for all considered parameters except incidence time of $u_{\max 1}$, which is around $5 \%$ for benchmark case 2 . The verification studies showed that the VOF solver used in the present study is able to predict the benchmark results for bubble rise for both low and high surface tension fluids.

\subsection{Experimental validation of solver}

The experimental validation of solver is carried out with experimental correlations [29] available in literature for bubble terminal velocity. Figure 4 shows the validation of Froude number $\left(F r=\frac{U_{T}}{\sqrt{g d_{B}}}\right)$ for air-water system as a function of bubble diameter to domain width ratio $\left(\frac{d_{B}}{W}\right)$. Validation is carried out for an air bubble diameter of $20 \mathrm{~mm}$ rising in water column for bubble diameter to domain width ratios of 0.125 and 0.4. A good comparison is

Table 3. Verification of present study with benchmark results for high surface tension case 1 .

\begin{tabular}{|c|c|c|c|}
\hline & \multicolumn{2}{|c|}{$\begin{array}{c}\text { Maximum rise } \\
\text { velocity }\end{array}$} & \multirow{2}{*}{$\begin{array}{c}\text { center of mass } \\
\text { position } \\
(\mathrm{m}) \text { at } t=3 \mathrm{~s}\end{array}$} \\
\hline & $t(\mathrm{~s})$ & $u_{\max }(\mathrm{m} / \mathrm{s})$ & \\
\hline present study $(1 / h=40)$ & 0.941 & 0.236 & 1.062 \\
\hline present study $(1 / h=80)$ & 0.938 & 0.236 & 1.063 \\
\hline present study $(1 / h=160)$ & 0.944 & 0.237 & 1.065 \\
\hline present study $(1 / h=320)$ & 0.967 & 0.236 & 1.069 \\
\hline $\mathrm{TP} 2 \mathrm{D}$ & 0.921 & 0.242 & 1.081 \\
\hline FreeLIFE & 0.931 & 0.242 & 1.080 \\
\hline MooNMD & 0.924 & 0.242 & 1.081 \\
\hline Hysing et al & 0.927 & 0.242 & 1.081 \\
\hline Štrubelj et al & 0.924 & 0.246 & 1.068 \\
\hline Klostermann et al & 0.952 & 0.235 & 1.070 \\
\hline
\end{tabular}

Table 4. Verification of present study with benchmark results for low surface tension case 2 .

\begin{tabular}{|c|c|c|c|c|c|}
\hline & \multicolumn{4}{|c|}{ Maximum rise velocity } & \multirow{2}{*}{$\begin{array}{c}\text { center of mass } \\
\text { position }(\mathrm{m}) \text { at } \\
t=3 \mathrm{~s}\end{array}$} \\
\hline & $t(\mathrm{~s})$ & $\begin{array}{l}u_{\max 1} \\
(\mathrm{~m} / \mathrm{s})\end{array}$ & $t(\mathrm{~s})$ & $\begin{array}{l}u_{\max 2} \\
(\mathrm{~m} / \mathrm{s})\end{array}$ & \\
\hline $\begin{array}{l}\text { present study } \\
(1 / h=40)\end{array}$ & 0.767 & 0.249 & 1.706 & 0.218 & 1.099 \\
\hline $\begin{array}{l}\text { present study } \\
(1 / h=80)\end{array}$ & 0.753 & 0.245 & 1.872 & 0.225 & 1.104 \\
\hline $\begin{array}{l}\text { present study } \\
\quad(1 / \\
\quad h=160)\end{array}$ & 0.746 & 0.242 & 1.953 & 0.230 & 1.111 \\
\hline $\begin{array}{l}\text { present study } \\
\quad(1 / \\
\quad h=320)\end{array}$ & 0.749 & 0.244 & 2.003 & 0.234 & 1.119 \\
\hline TP2D & 0.733 & 0.252 & 2.07 & 0.243 & 1.138 \\
\hline FreeLIFE & 0.728 & 0.251 & 1.984 & 0.244 & 1.125 \\
\hline MooNMD & 0.732 & 0.250 & 2.06 & 0.239 & 1.139 \\
\hline $\begin{array}{l}\text { Klostermann } \\
\text { et al }\end{array}$ & 0.716 & 0.247 & 2.005 & 0.235 & 1.122 \\
\hline
\end{tabular}

obtained between the numerical prediction and experimental correlation as shown in figure 4, confirming the validation of interFoam solver for present study.

\section{Grid independence}

A grid independence study is carried out to find the grid size required for simulating an initially static spherical bubble that rises in a quiescent liquid sodium pool. Argon gas bubble of initial diameter $20 \mathrm{~mm}$ is considered for the study. The domain width and height considered for the study is $160 \mathrm{~mm}$. The thermo physical properties of argon (Ar) and sodium $(\mathrm{Na})$ are evaluated at $473 \mathrm{~K}$. The grid independence for the present system is carried out by simulating the case for three grid sizes $512 \times 512$ (coarse), $544 \times 544$ (medium) and $576 \times 576$ (fine). The results of the study for various grid sizes are compared in figure 5 . Figures 5(a) and 5(b) showed that average bubble rise velocity and center of mass position are almost same for all three grid sizes studied. Hence, domain with grid size of $544 \times 544$ is chosen for the present study considering the grid independence achieved and higher computational cost involved in finer mesh studies. The computational time required for simulating a grid size of $544 \times 544$ is 4 days.

\section{Results and discussion}

The numerical simulation of inert gas bubble dynamics in liquid sodium $/ \mathrm{NaK}$ pool is studied parametrically to understand the effect of bubble size, domain aspect ratios and gas-liquid components. The sensitivity studies are 


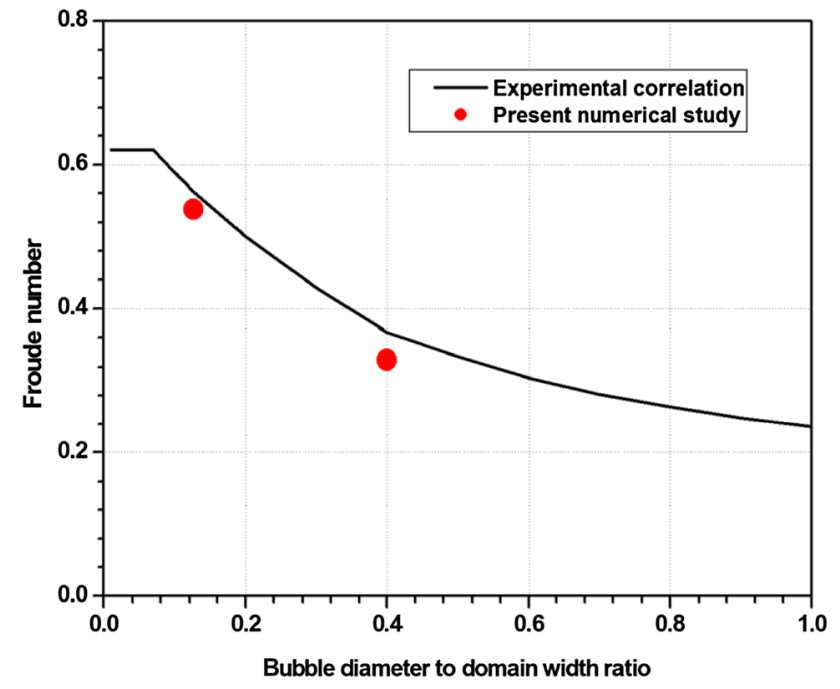

Figure 4. Validation of interFoam solver for bubble terminal velocity in air-water system.

carried out considering $20 \mathrm{~mm}$ bubble diameter as the base case for the range of bubble sizes typical to SFR for source term evaluation $[16,17]$. The evaluation is classified into the following sections.

\subsection{Effect of bubble size}

The bubble rising behavior is size dependent and its shape is related to the following dimensionless parameters.

Morton number which depends on fluid properties is given by:

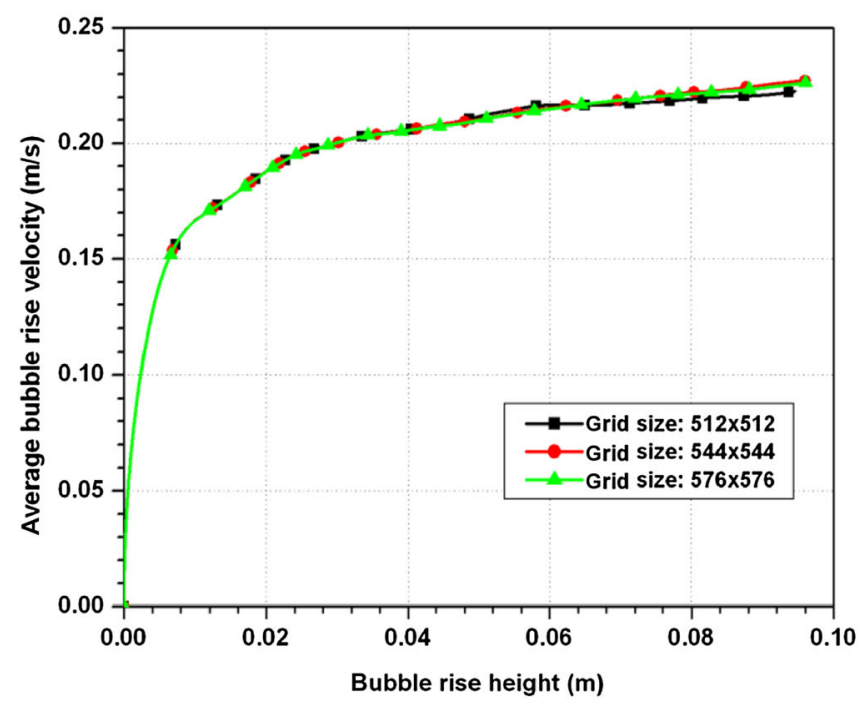

(a)

$$
M o=\frac{g \mu_{l}^{4}}{\rho_{l} \sigma^{3}}
$$

The Eötvös number, which represents the ratio of gravitational to surface tension force, is given by:

$$
E o=\frac{g \rho_{l} d_{B}^{2}}{\sigma}
$$

The Reynolds number, which represents the ratio of inertial to viscous force, is given by:

$$
R e=\frac{d_{B} U_{T} \rho_{l}}{\mu_{l}}
$$

The Capillary number, which represents the ratio of viscous to surface tension force, is given by:

$$
\mathrm{Ca}=\frac{\mu_{l} U_{T}}{\sigma}
$$

Numerical simulations are carried out to understand the effect of initial bubble diameter on bubble dynamics for argon gas and liquid sodium system at $473 \mathrm{~K}$. The domain height ' $H$ ' and width ' $W$ ' are taken as " $8 d_{B}$ " so that the bubble reaches terminal velocity and side wall effects can be ignored [12]. The different bubble diameters considered for the analysis are $10 \mathrm{~mm}, 15 \mathrm{~mm}$ and $20 \mathrm{~mm}$. The nondimensional parameters for bubble dynamics are evaluated from the characteristic bubble velocity [11], $U_{T}=\sqrt{g d_{B}}$ as shown in table 5 .

The simulation results of bubble rising trajectories and shapes in the liquid sodium for different bubble sizes are depicted in figure 6 . The rise time, number of elements and computing time for various bubble diameters in the present study are given in table 6 . Figures 6(a)-(c) show that for the

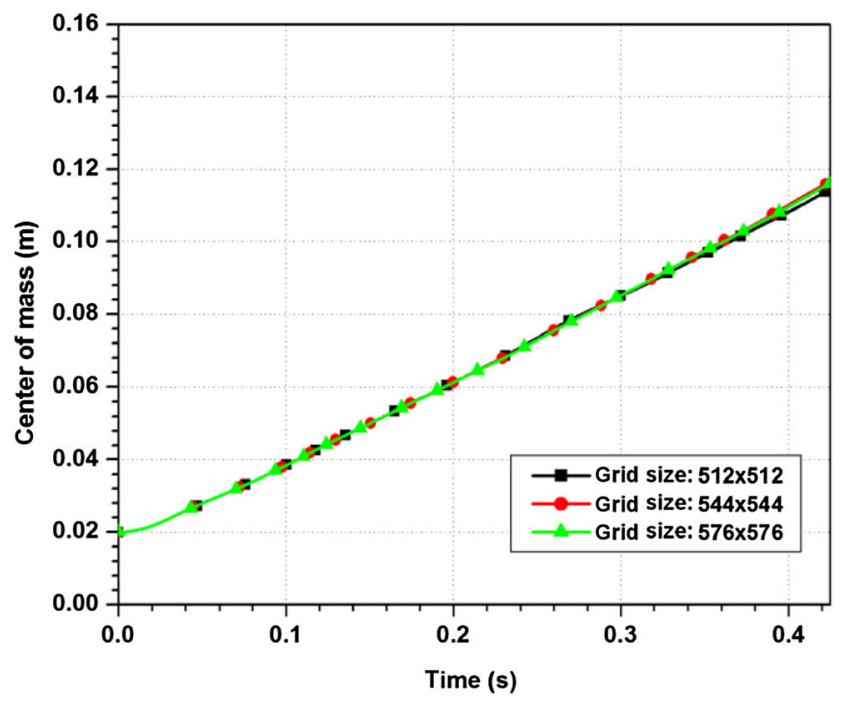

(b)

Figure 5. Grid independence study cases with different mesh sizes for (a) average rise velocity with rise height (b) center of mass position with time for rising bubble. 
Table 5. Bubble conditions for argon-sodium system.

\begin{tabular}{lcrrc}
\hline$d_{B}(\mathrm{~mm})$ & Mo & \multicolumn{1}{c}{$R e$} & \multicolumn{1}{c}{ Eo } & Ca \\
\hline 10 & $6.7 \times 10^{-14}$ & 6262.0 & 4.7 & $7.5 \times 10^{-4}$ \\
15 & $6.7 \times 10^{-14}$ & 11505.7 & 10.6 & $9.1 \times 10^{-4}$ \\
20 & $6.7 \times 10^{-14}$ & 17714.0 & 18.8 & $1.1 \times 10^{-3}$ \\
\hline
\end{tabular}

range of bubble sizes studied, $20 \mathrm{~mm}$ bubble movement is relatively stable and its rising trajectory is almost rectilinear. The temporal variation of bubble dynamic parameters and rise trajectory for center of mass position of bubble diameters ranging from 10 to $20 \mathrm{~mm}$ are shown in figures 7 and 8 . Figure 7 shows that the bubble rise velocity reaches $0.2 \mathrm{~m} / \mathrm{s}$ in $0.104 \mathrm{~s}, 0.062 \mathrm{~s}$ and $0.025 \mathrm{~s}$ for $10 \mathrm{~mm}, 15 \mathrm{~mm}$ and $20 \mathrm{~mm}$ bubble, respectively.
The oscillations in the bubble vertical velocity component are seen and are due to the influence of horizontal velocity components (figure 7). The oscillations are found to be more pronounced for lower bubble sizes and the amplitude is observed to decrease with increase in bubble diameter. The maximum deviations in rise velocities for $10 \mathrm{~mm}$ and $15 \mathrm{~mm}$ bubble sizes from $20 \mathrm{~mm}$ case are observed to decrease with increase in bubble diameter. It can be seen that the maximum deviations in rise velocity of $10 \mathrm{~mm}$ and $15 \mathrm{~mm}$ from the $20 \mathrm{~mm}$ bubble case are $31.6 \%$ and $28.1 \%$, respectively as shown in figure 7 .

The deviation from rectilinear motion is least for $20 \mathrm{~mm}$, with a maximum deviation of $0.0009 \mathrm{~m}$ from the central axis at $0.425 \mathrm{~s}$ as shown in figure 8(a). Figure 8(a) signifies that the bubble rise becomes rectilinear for argon-sodium system at a diameter of $20 \mathrm{~mm}$. The maximum horizontal

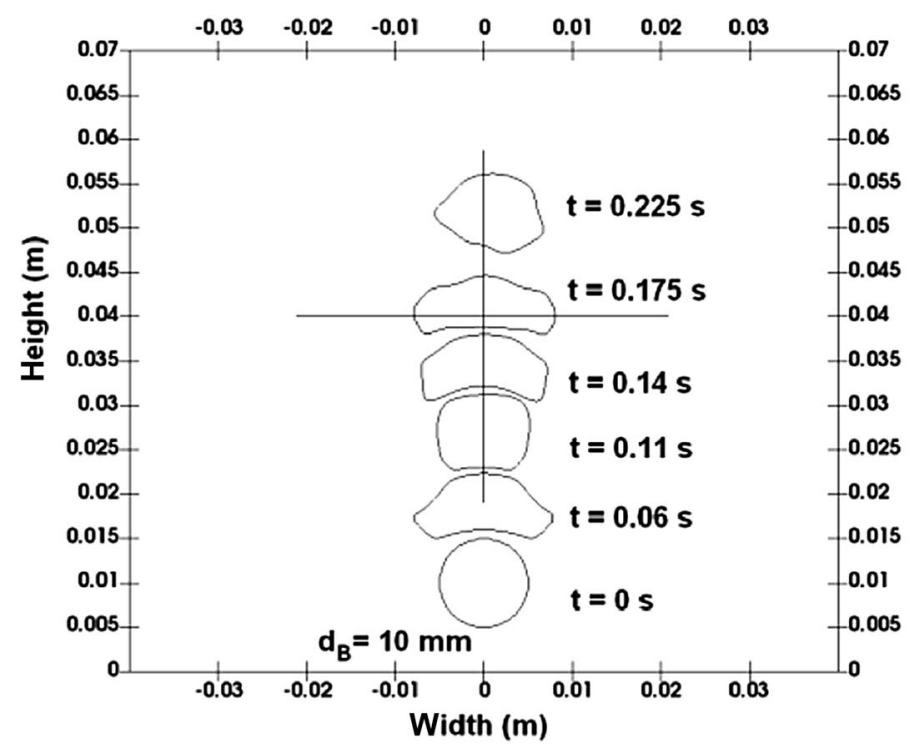

(a)

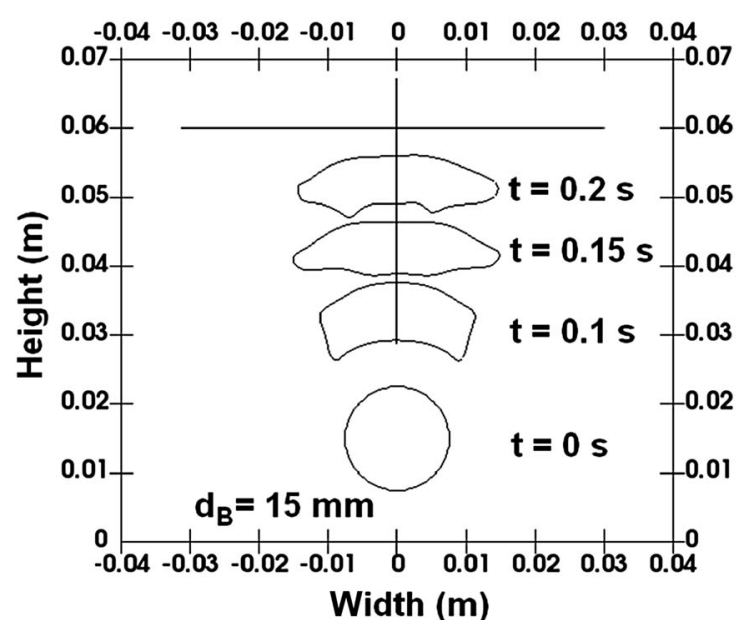

(b)

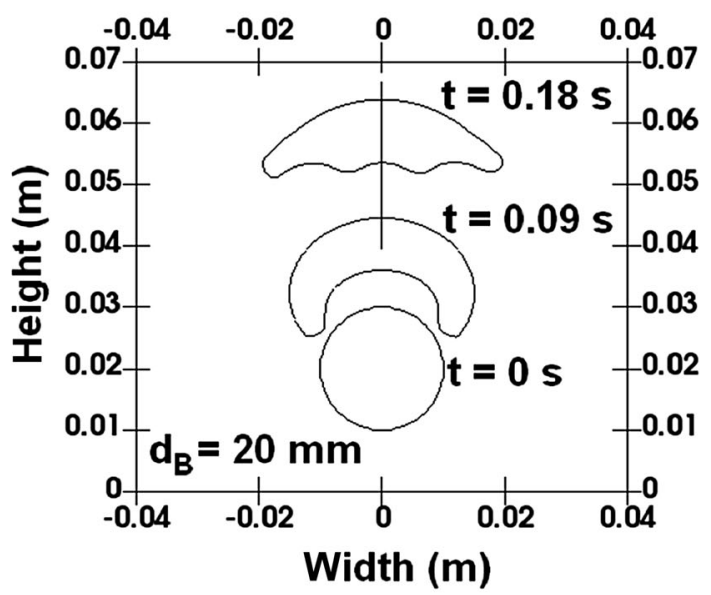

(c)

Figure 6. Bubble rising trajectories for (a) $10 \mathrm{~mm}$, (b) $15 \mathrm{~mm}$ and (c) $20 \mathrm{~mm}$. 
Table 6. Number of elements and computation time for argonsodium system with Aspect Ratio $(A R)=1$.

\begin{tabular}{lccc}
\hline$d_{B}(\mathrm{~mm})$ & Rise time $(\mathrm{s})$ & $n_{\text {elements }}$ & Computation time \\
\hline 10 & 0.225 & 295936 & 4 days \\
15 & 0.350 & 295936 & 4 days \\
20 & 0.425 & 295936 & 4 days \\
\hline
\end{tabular}

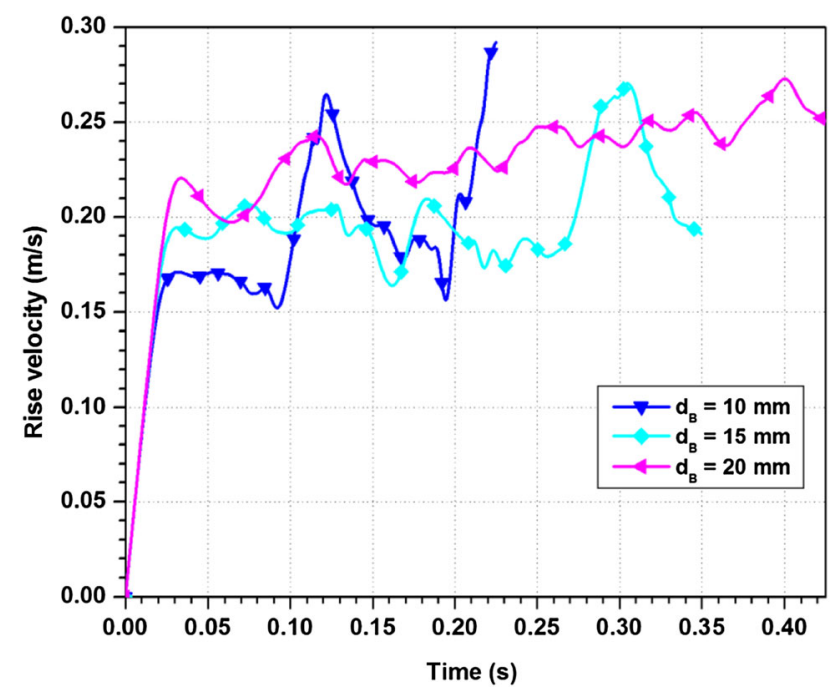

Figure 7. Temporal variation of rise velocity for various bubble diameters in argon-sodium system.

deviations from the central axis are also given in table 7. It can be seen that the deviation for $20 \mathrm{~mm}$ is $1.14 \%$ of the half width of the domain cavity. Since, the horizontal deviation from central axis is least for $20 \mathrm{~mm}$ bubble; its
Table 7. Maximum horizontal deviation from central axis for argon-sodium system with $A R=1$.

\begin{tabular}{lcc}
\hline $\begin{array}{l}\text { Maximum horizontal } \\
(\mathrm{mm})\end{array}$ & $\begin{array}{c}\text { \% of horizontal deviation } \\
\text { deviation from central } \\
\text { axis }(\mathrm{m})\end{array}$ & $\begin{array}{c}\text { w.r.t half width of domain } \\
\text { cavity }\end{array}$ \\
\hline 10 & $9.8 \times 10^{-4}$ & 2.5 \\
15 & $6.2 \times 10^{-3}$ & 10.3 \\
20 & $9.1 \times 10^{-4}$ & 1.1 \\
\hline
\end{tabular}

rise trajectory is rectilinear compared to $10 \mathrm{~mm}$ and $15 \mathrm{~mm}$ bubbles sizes. Figure 8(b) shows the temporal variation of center of mass position for bubble sizes $10 \mathrm{~mm}, 15 \mathrm{~mm}$ and $20 \mathrm{~mm}$. The initial offset at time, $t=0 \mathrm{~s}$ is due to the differences in initial sizes and elevation. Figure 8(b) shows that at $0.225 \mathrm{~s}$, the $20 \mathrm{~mm}$ bubble travels vertically $0.047 \mathrm{~m}$. At $t=0.225 \mathrm{~s}$, the distance travelled vertically by $10 \mathrm{~mm}$ bubble is lower than that of $20 \mathrm{~mm}$ bubble by $12.14 \%$ due its lower rise velocity. The average bubble terminal velocity is found to be $0.21 \mathrm{~m} / \mathrm{s}$ for bubble diameters ranging from 10 to $20 \mathrm{~mm}$. The highest value of bubble terminal velocity is $0.24 \mathrm{~m} / \mathrm{s}$ for $20 \mathrm{~mm}$ bubble and the lowest is $0.18 \mathrm{~m} / \mathrm{s}$ for $10 \mathrm{~mm}$ bubble as shown in figure 9 .

\subsection{Effect of domain aspect ratio}

Simulations are carried out to understand the effect of domain Aspect Ratio $(A R)$ on bubble dynamics for argonsodium system. The influence of $A R$ on bubble dynamics is

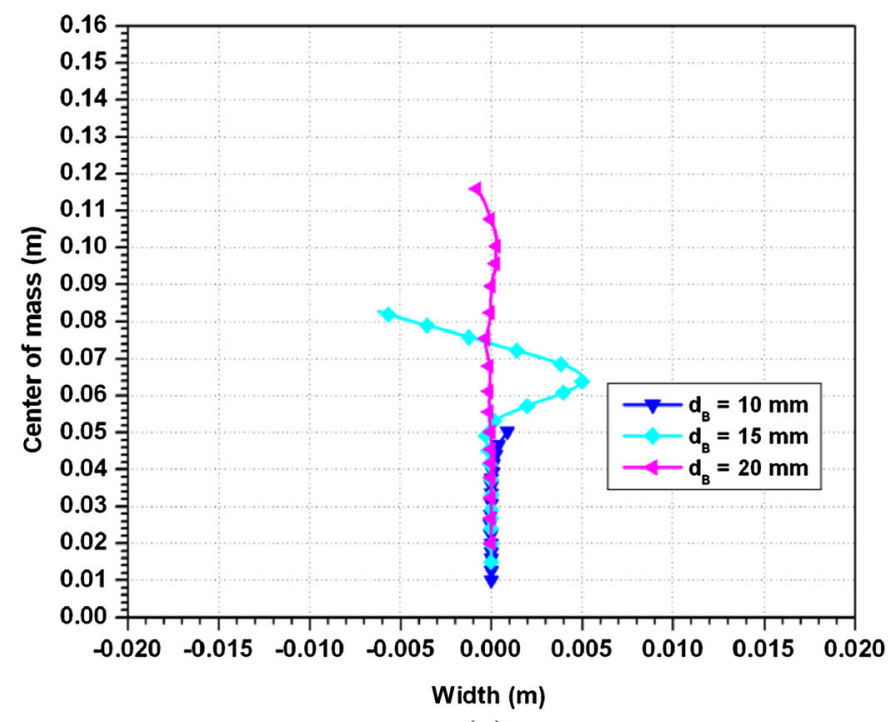

(a)

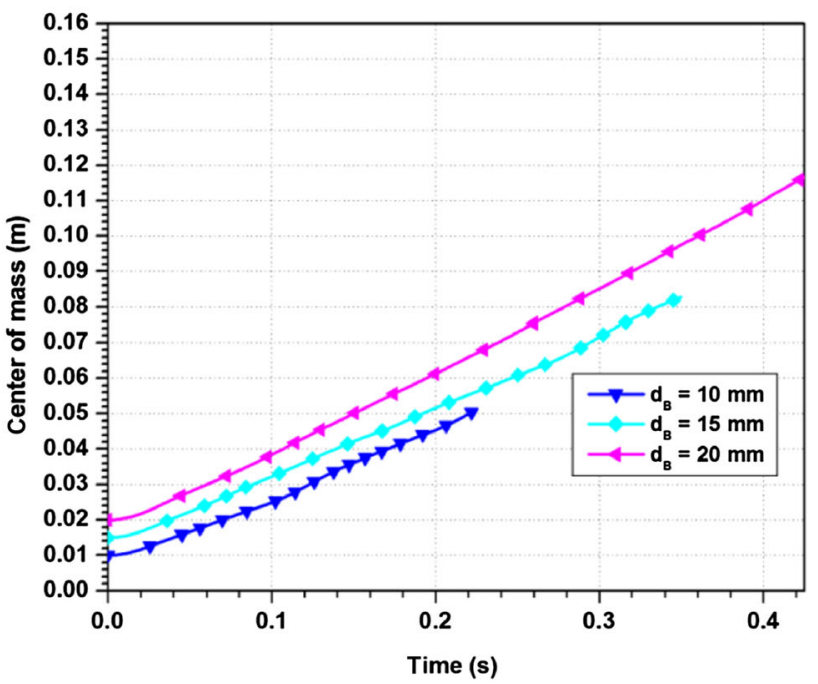

(b)

Figure 8. (a) Lateral position of center of mass, (b) Axial position of center of mass with time for argon-sodium system. 
studied in detail by varying the domain height and width independently.

6.2a Effect of domain height: The aspect ratio is varied by changing the height of the domain for a fixed domain width of $160 \mathrm{~mm}$. The three different domain aspect ratios considered for the analysis are 1, 1.25 and 1.5 for a fixed bubble diameter of $20 \mathrm{~mm}$. The temporal variation of bubble dynamics as a function of cavity aspect ratio is given in figures 10 and 11 . Figure 10 shows that $20 \mathrm{~mm}$ bubble rise velocity reaches $0.2 \mathrm{~m} / \mathrm{s}$ in $0.025 \mathrm{~s}$ for all the aspect ratios studied. The maximum horizontal deviation from the central axis is $4 \%$ of the half width of the domain cavity and is insignificant as evident from figure 11(a). Thus, irrespective of the aspect ratio studied, the rise trajectory of the $20 \mathrm{~mm}$ bubble is rectilinear. Figure 11(b) also indicates that the rise height for $A R=1.5$ is less than $1.13 \%$ as compared to $A R=1$ at $0.425 \mathrm{~s}$ and hence the deviation is insignificant. The average bubble terminal velocity is $0.23 \mathrm{~m} / \mathrm{s}$ for aspect ratio of 1 to 1.5 for varying domain height as shown in figure 12 . The bubble terminal velocity is found to be $0.238 \mathrm{~m} / \mathrm{s}$ and $0.235 \mathrm{~m} / \mathrm{s}$ for $A R=1$ and 1.5 , respectively, the deviation between them being insignificant. The variation of average bubble rise velocity with rise height of $20 \mathrm{~mm}$ bubble for varying aspect ratios as a function of domain height are given in figure 13. It is clear that the domain height of $8 d_{B}$ is sufficient for bubble dynamic simulation in the present study.

6.2b Effect of domain width: Results on the effect of domain width on bubble dynamics for a fixed domain height of $160 \mathrm{~mm}$ are presented in this section. The three different domain aspect ratios considered for the analysis are $0.73,1$ and 1.6 for a fixed bubble diameter of $20 \mathrm{~mm}$. The temporal variation of bubble dynamics as a function of

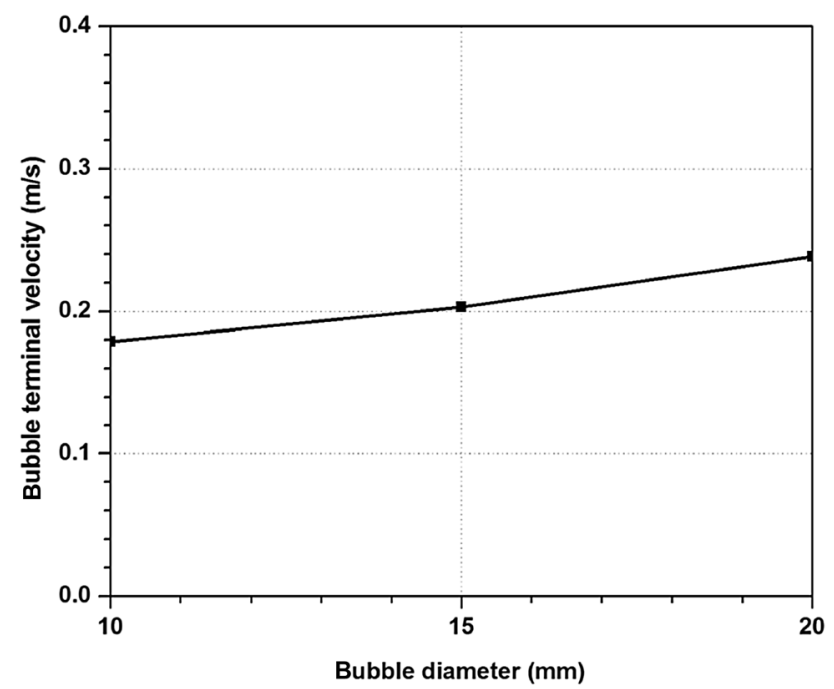

Figure 9. Bubble terminal velocity with bubble diameter for argon-sodium system.

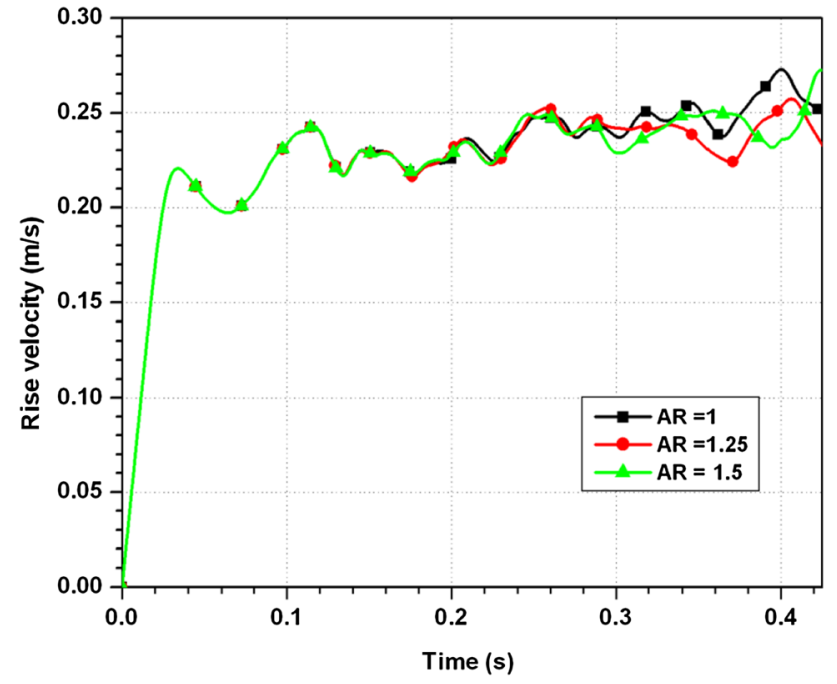

Figure 10. Temporal variation of rise velocity for various domain aspect ratios in argon-sodium system for $20 \mathrm{~mm}$ bubble.

cavity aspect ratio is given in figures 14 and 15 . Figure 14 shows that $20 \mathrm{~mm}$ bubble rise velocity reaches $0.2 \mathrm{~m} / \mathrm{s}$ in $0.025 \mathrm{~s}$ for all the aspect ratios studied. From figure 15(a), the maximum horizontal deviation from the central axis for the ARs studied is $4.2 \%$ of the half width of the domain cavity for aspect ratio of 0.73 and the least deviation is $0.75 \%$ for aspect ratio of 1.6 , which is insignificant. Thus, for aspect ratios of 1 and 1.6, the rise trajectory of the $20 \mathrm{~mm}$ bubble is rectilinear. The rise height for the case of $A R=1$ and 1.6 is $10.1 \%$ and $1.9 \%$ lower than that for $A R=0.73$ at $0.425 \mathrm{~s}$ as shown in figure $15(\mathrm{~b})$. The average bubble terminal velocity is $0.24 \mathrm{~m} / \mathrm{s}$ for aspect ratio varying from $0.73-1.6$ as shown in figure 16 for varying domain width. The bubble terminal velocity of $0.22 \mathrm{~m} / \mathrm{s}$ is obtained for $A R=1.6$, which is $13.6 \%$ lower than the bubble terminal velocity of $0.25 \mathrm{~m} / \mathrm{s}$ for $A R=0.73$. The variation of average bubble rise velocity with rise height of $20 \mathrm{~mm}$ bubble for varying aspect ratios as a function of domain width are given in figure 17 . The study confirms that a minimum domain width, $W=8 d_{B}$ is to be provided to avoid wall effects as suggested in literature [12].

\subsection{Effect of gas-liquid component}

Numerical simulations are carried out to understand the effect of various gas-liquid system components on bubble dynamics. The gas-liquid systems considered for the analysis are argon-sodium system at $473 \mathrm{~K}$, xenon (Xe)-sodium system at $820 \mathrm{~K}$ and $\operatorname{argon-NaK}$ system at $303 \mathrm{~K}[2,3]$. The domain height ' $H$ ' and width ' $W$ ' are taken as " $8 d_{B}$ ". The bubble diameter considered for the analysis is $20 \mathrm{~mm}$. The transport properties of the gas-liquid systems considered for analysis are shown in table 8 . The bubble dynamics as a function of gas-liquid component is given in 


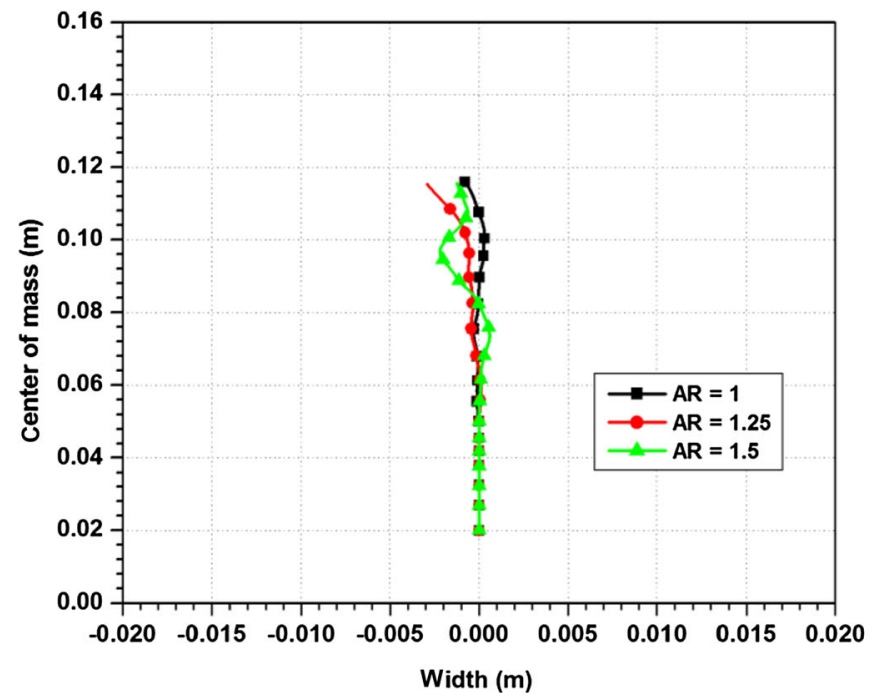

(a)

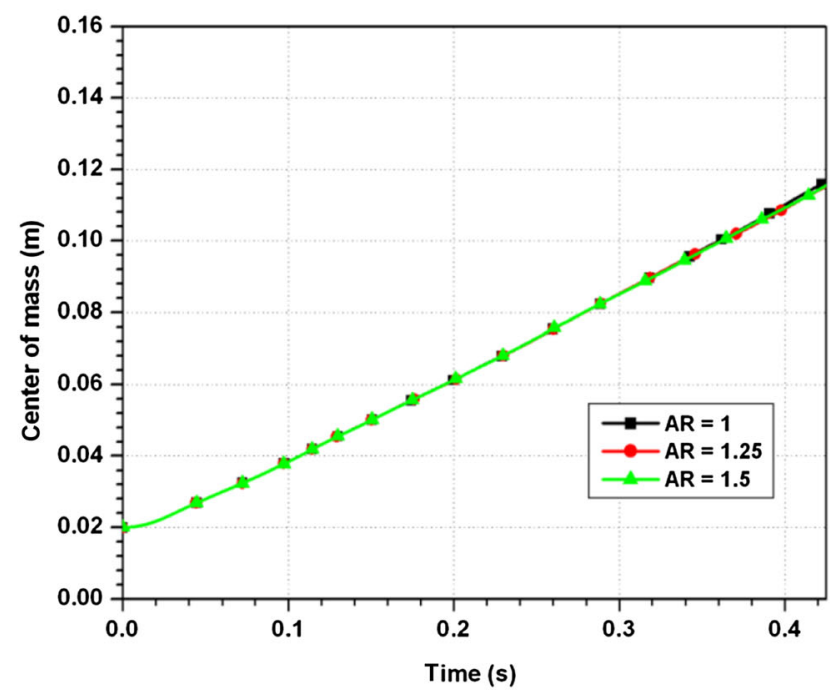

(b)

Figure 11. (a) Lateral position of center of mass. (b) Axial position of center of mass with time for $20 \mathrm{~mm}$ bubble.

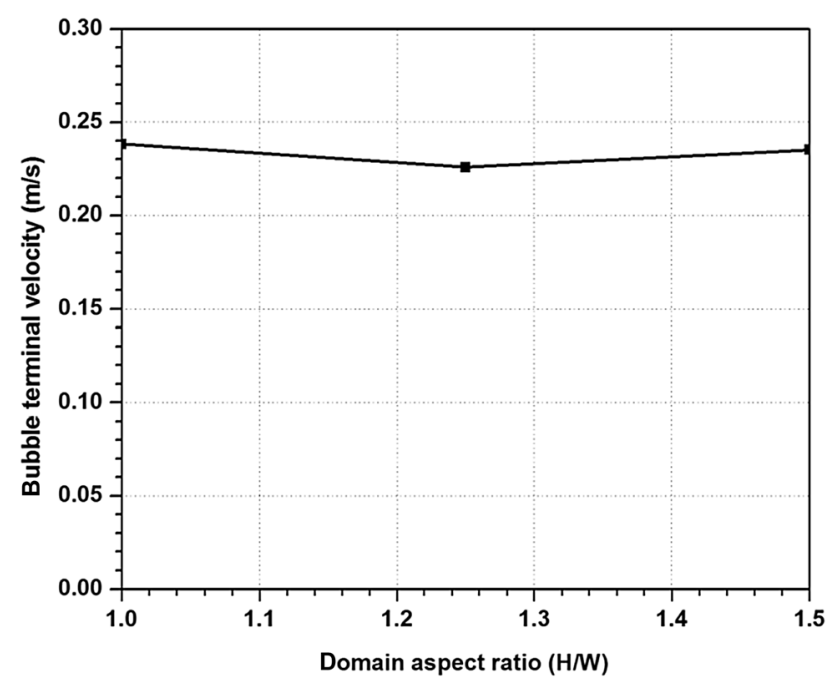

Figure 12. Bubble terminal velocity with domain aspect ratio for $20 \mathrm{~mm}$ bubble.

figures 18 and 19. Figure 18 shows that the bubble rise velocity reaches $0.2 \mathrm{~m} / \mathrm{s}$ in $0.025 \mathrm{~s}$ for all the three gasliquid systems studied. The maximum deviation in rise velocities for various gas-liquid components from the argon-sodium system case is observed to decrease with increase in surface tension. It can be seen that the rise velocities of xenon-sodium system $(\sigma=0.155 \mathrm{~N} / \mathrm{m})$ and argon-NaK system $(\sigma=0.177 \mathrm{~N} / \mathrm{m})$ are lower than argonsodium system $(\sigma=0.189 \mathrm{~N} / \mathrm{m})$ by $19 \%$ at $0.26 \mathrm{~s}$ and $13 \%$ at $0.41 \mathrm{~s}$, respectively.

From figure 19(a), the maximum horizontal deviation from the central axis for the gas-liquid component studied is $5 \%$ of the half width of the domain cavity for argon- $\mathrm{NaK}$

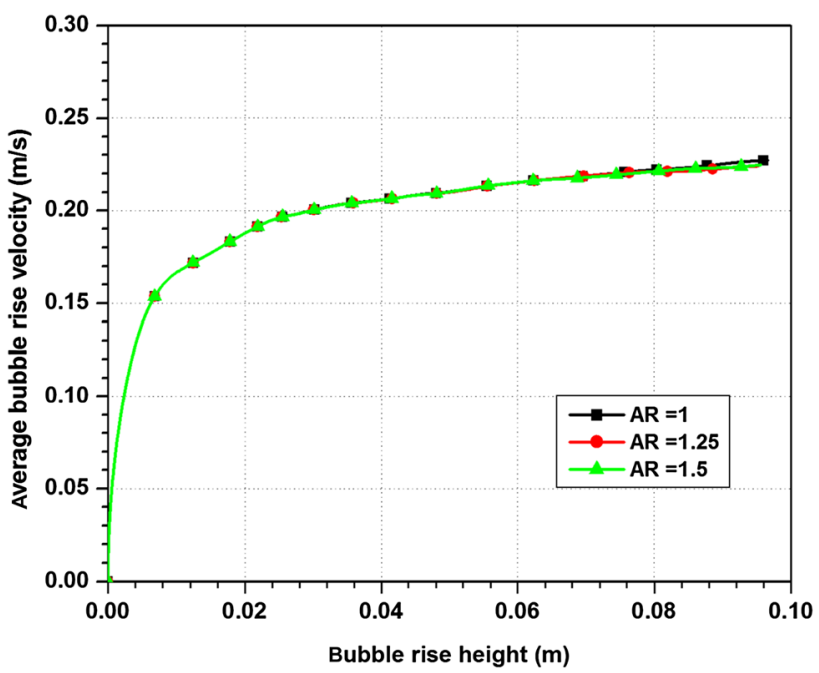

Figure 13. Variation of average bubble rise velocity with rise height for $20 \mathrm{~mm}$ bubble.

system. Thus, irrespective of the gas-liquid component studied, the rise trajectory of the $20 \mathrm{~mm}$ bubble is rectilinear. Figure 19(b) shows that the maximum bubble rise height is for argon-sodium system at $0.425 \mathrm{~s}$. The rise height for xenon-sodium system is $1.66 \%$ lower than that for argon-sodium system and is hence insignificant. Hence, from the parametric study it is clear that the effect of gasliquid component on bubble dynamics is insignificant for the $20 \mathrm{~mm}$ bubble diameter. The average bubble terminal velocity remains almost constant $(0.24 \mathrm{~m} / \mathrm{s})$ with varying gas-liquid system component as shown in figure 20. The bubble terminal velocity is $0.238 \mathrm{~m} / \mathrm{s}$ for argon-sodium system and $0.236 \mathrm{~m} / \mathrm{s}$ for xenon-sodium system, with the deviation being insignificant. 


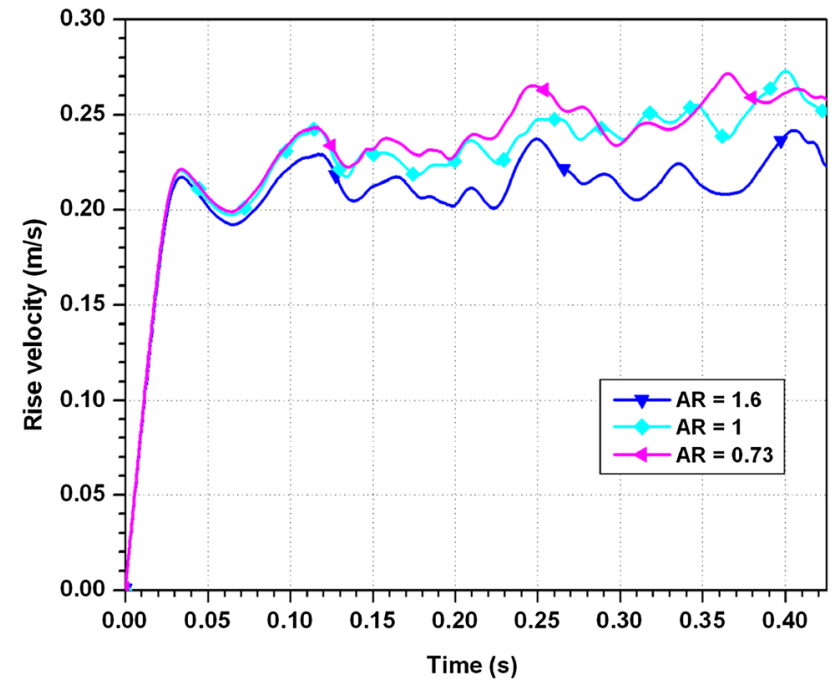

Figure 14. Temporal variation of rise velocity for various domain aspect ratios in argon-sodium system for $20 \mathrm{~mm}$ bubble.

\subsection{Bubble dynamics in water and sodium}

Comparison of bubble dynamics between air-water system and argon-sodium system for $20 \mathrm{~mm}$ initial bubble diameter is carried out to understand the similarity between normal liquid and liquid metal single bubble dynamics. The transport properties of fluids used for simulating air-water system and argon-sodium system are shown in table 9. The temporal variations of bubble dynamics for $20 \mathrm{~mm}$ airwater and argon-sodium systems are shown in figures 21 and 22. The bubble contour for $20 \mathrm{~mm}$ bubble at $t=0.425 \mathrm{~s}$ is depicted in figure 23 , for both air-water and argon-sodium systems.

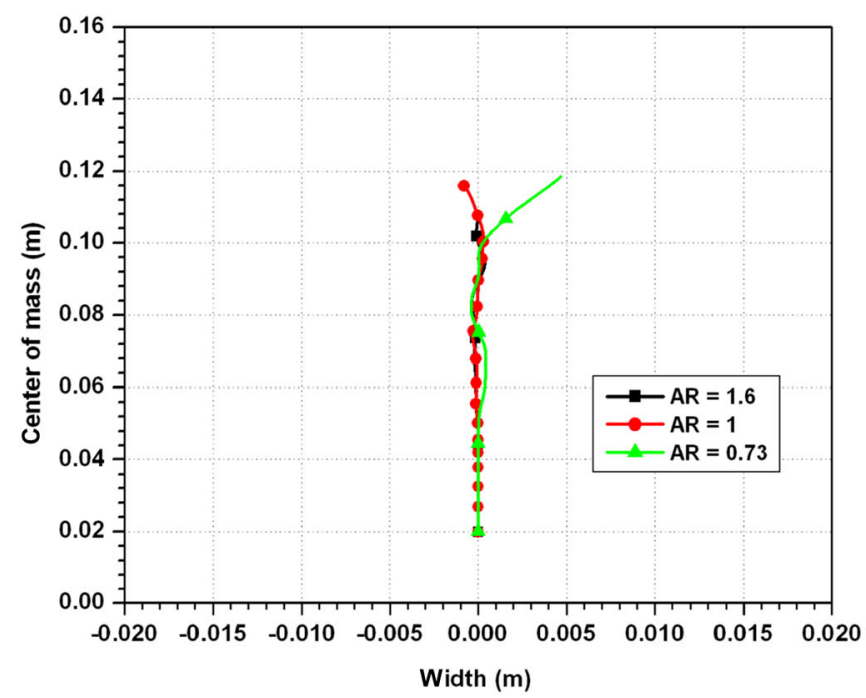

(a)

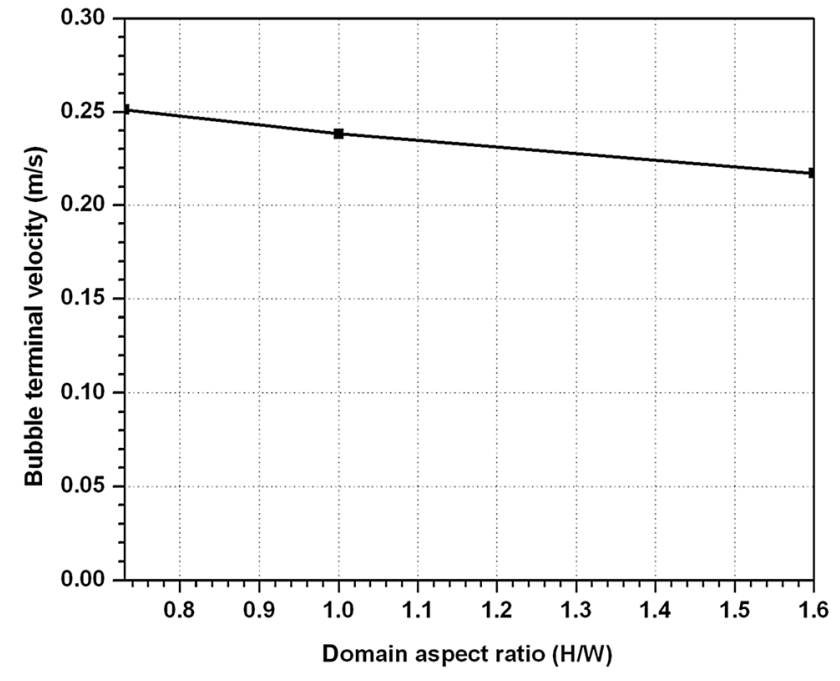

Figure 16. Bubble terminal velocity with domain aspect ratio for $20 \mathrm{~mm}$ bubble.

Figure 21 shows that the rise velocity reaches $0.2 \mathrm{~m} / \mathrm{s}$ in $0.025 \mathrm{~s}$ for both air-water and argon-sodium systems respectively. The maximum deviation in rise velocity for air-water from argon-sodium system is $39 \%$ and occurs at $0.135 \mathrm{~s}$ due to breakup. The deviation from rectilinear motion is lower for air-water system, with a maximum deviation of $0.0003 \mathrm{~m}$ from the central axis at $0.425 \mathrm{~s}$ and higher for argon-sodium system, with a maximum deviation of $0.0009 \mathrm{~m}$ from the central axis at $0.425 \mathrm{~s}$, as shown in figure 22(a). The maximum horizontal deviation from the central axis for argon-sodium system is $1.14 \%$ of the half width of the domain cavity and is insignificant. Thus for both systems the rise trajectory of the $20 \mathrm{~mm}$ bubble is rectilinear. Figure 22(b) shows that at $0.425 \mathrm{~s}$

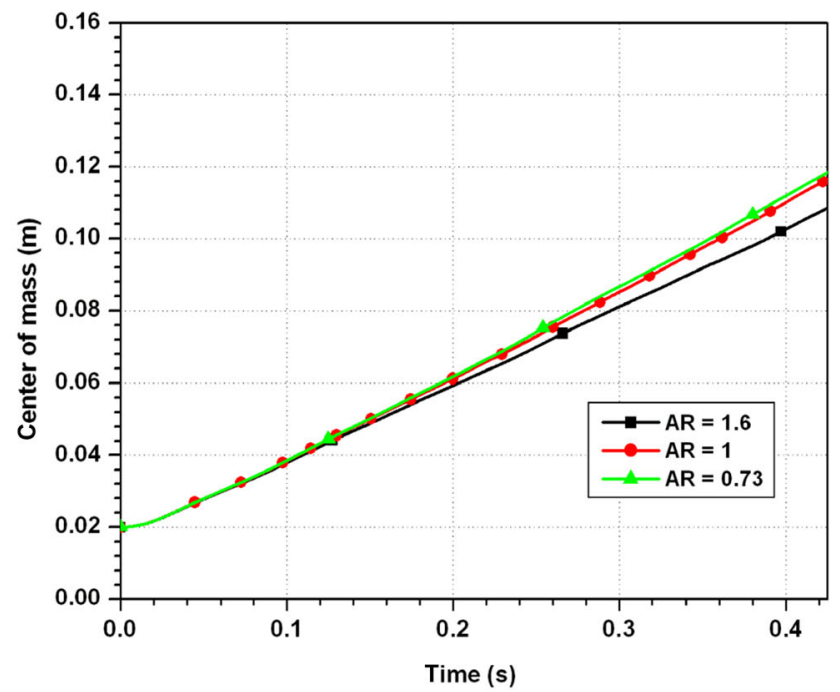

(b)

Figure 15. (a) Lateral position of center of mass. (b) Axial position of center of mass with time for $20 \mathrm{~mm}$ bubble. 


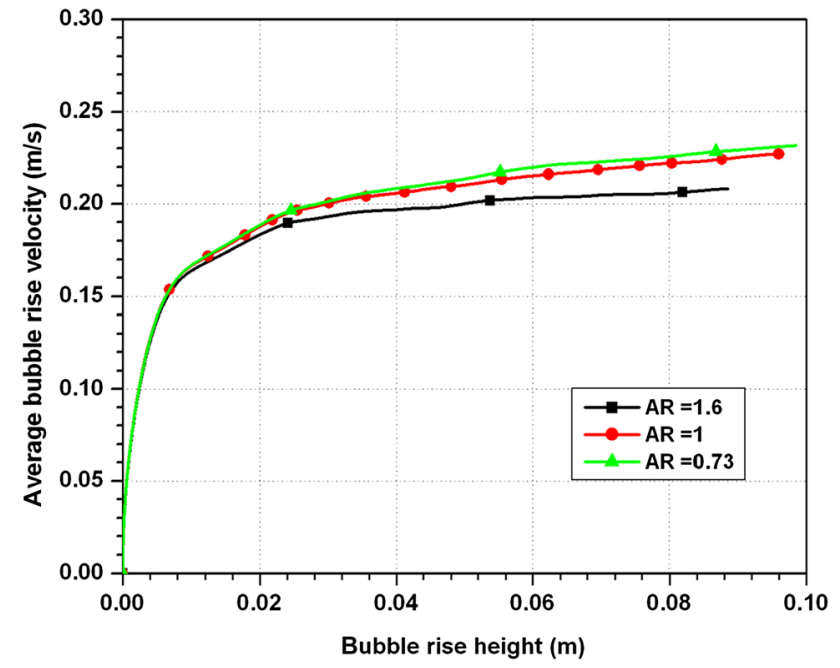

Figure 17. Variation of average bubble rise velocity with rise height for $20 \mathrm{~mm}$ bubble.

Table 8. Fluid properties for inert gas-liquid system.

\begin{tabular}{lccccc}
\hline & $\begin{array}{c}\rho_{1} \\
(\mathrm{~kg} /\end{array}$ & $\begin{array}{c}\rho_{2} \\
(\mathrm{~kg} /\end{array}$ & & & \\
& $\left.\mathrm{m}^{3}\right)$ & $\left.\mathrm{m}^{3}\right)$ & $\mu_{1}$ (Pa.s) & $\mu_{2}($ Pa.s $)$ & $\begin{array}{c}\sigma(\mathrm{N} / \\
\mathrm{m})\end{array}$ \\
\hline $\begin{array}{c}\text { Case } \\
\quad(T=473 \mathrm{~K})\end{array}$ & 904 & 1.04 & $4.5 \times 10^{-4}$ & $3.2 \times 10^{-5}$ & 0.189 \\
$\begin{array}{c}\text { Xenon-sodium } \\
(T=820 \mathrm{~K})\end{array}$ & 820 & 1.97 & $2.2 \times 10^{-4}$ & $5.6 \times 10^{-5}$ & 0.155 \\
$\begin{array}{c}\text { Argon-NaK } \\
(T=303 \mathrm{~K})\end{array}$ & 874 & 1.63 & $5.3 \times 10^{-4}$ & $2.8 \times 10^{-5}$ & 0.177 \\
\hline
\end{tabular}

the rise height of argon-sodium system are higher than that for air-water system. The rise height for air-water system is $3.03 \%$ lower than the rise height for argonsodium system and is hence insignificant. The bubble terminal velocity of $20 \mathrm{~mm}$ bubble in air-water system is $2.23 \%$ lower than that for argon-sodium system and is evaluated to be around $0.233 \mathrm{~m} / \mathrm{s}$. The bubble dynamic parameters for both the systems are observed to be similar except for the breakup.

Figure 23(a), (b) show that significant breakup to secondary bubbles occurs for the air-water system compared to the argon-sodium system. This suggests that the bubble breakup for liquids with lower surface tension occurs at lower diameters as predicted by Levich correlation [30].

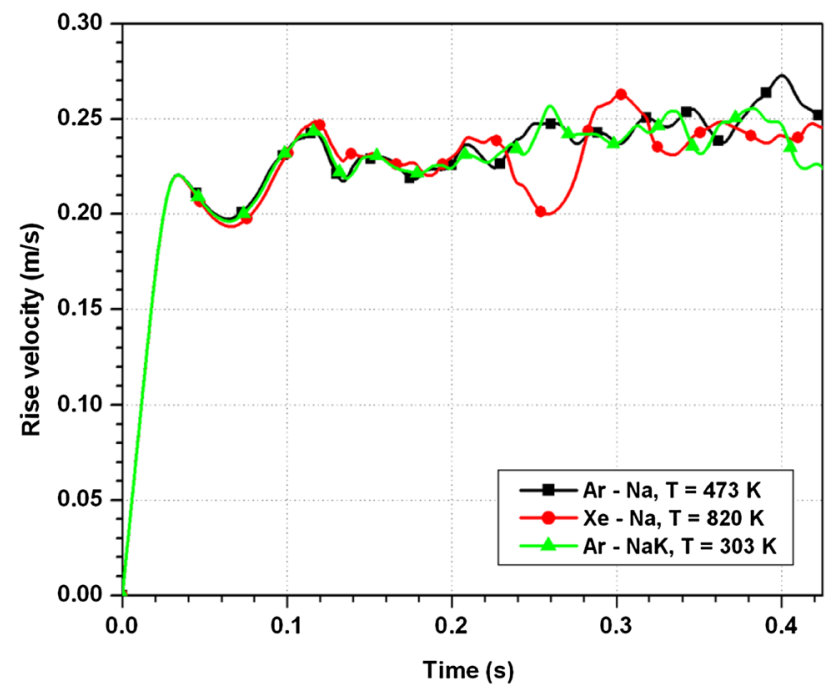

Figure 18. Temporal variation of rise velocity of $20 \mathrm{~mm}$ bubble for various gas-liquid systems.

The bubble bottom oscillations are stronger in argonsodium system than air-water system at $0.425 \mathrm{~s}$ as observed by comparing figure 23 (a) and $\mathrm{f} 23$ (b), respectively. This is due to the higher surface tension of sodium compared to water and is in concurrence with the study of Wang and Tong [9].

\section{Conclusions}

The interFoam solver of open source CFD package, OpenFOAM version 3.0.0 is used to simulate the rise dynamics of single gas bubble in liquid sodium pool. The VOF module of the solver along with the discretization schemes used in the present study is validated against the numerical benchmark data and experimental results available in literature for single bubble dynamics. The present study investigates the rise dynamics of inert gas bubble in liquid sodium/sodium-potassium alloy $(\mathrm{NaK})$ pool. Parametric studies are carried out to understand the effects of bubble diameter, domain aspect ratio and gas-liquid system on the bubble rise dynamics. The study shows that the bubble rise velocity increases with diameter for liquid sodium systems. The results predict that $20 \mathrm{~mm}$ bubble rises rectilinearly and is relatively stable for the range of domain aspect ratios and gas-liquid systems studied. The 


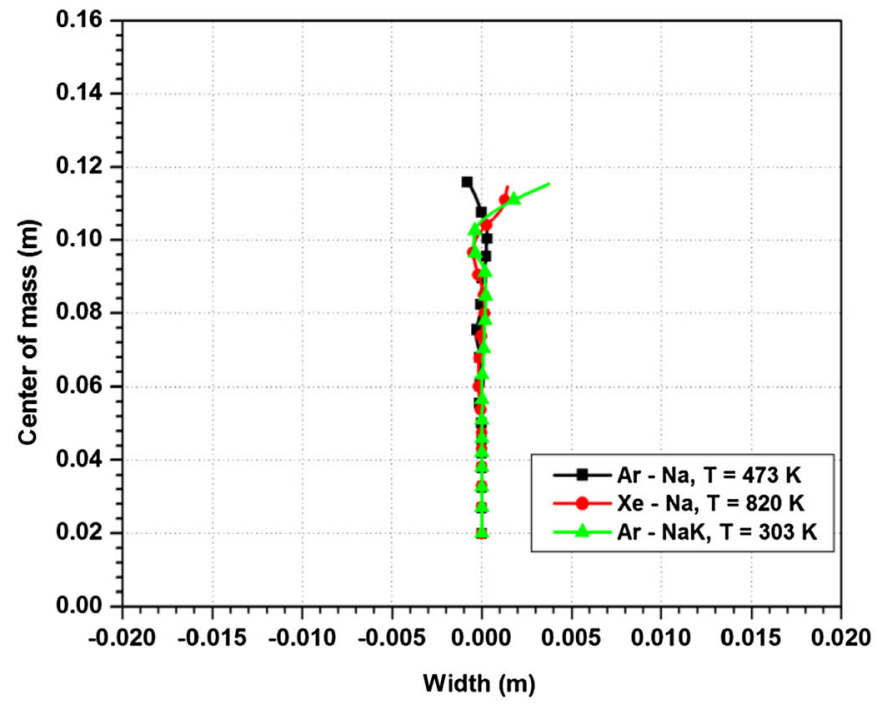

(a)

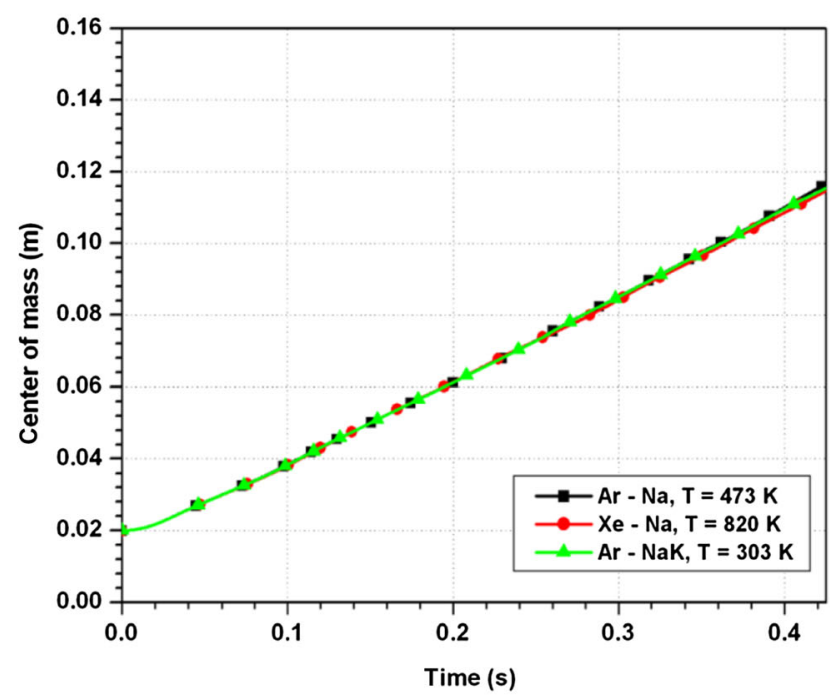

(b)

Figure 19. (a) Lateral position of center of mass. (b) Axial position of center of mass with time for $20 \mathrm{~mm}$ bubble.

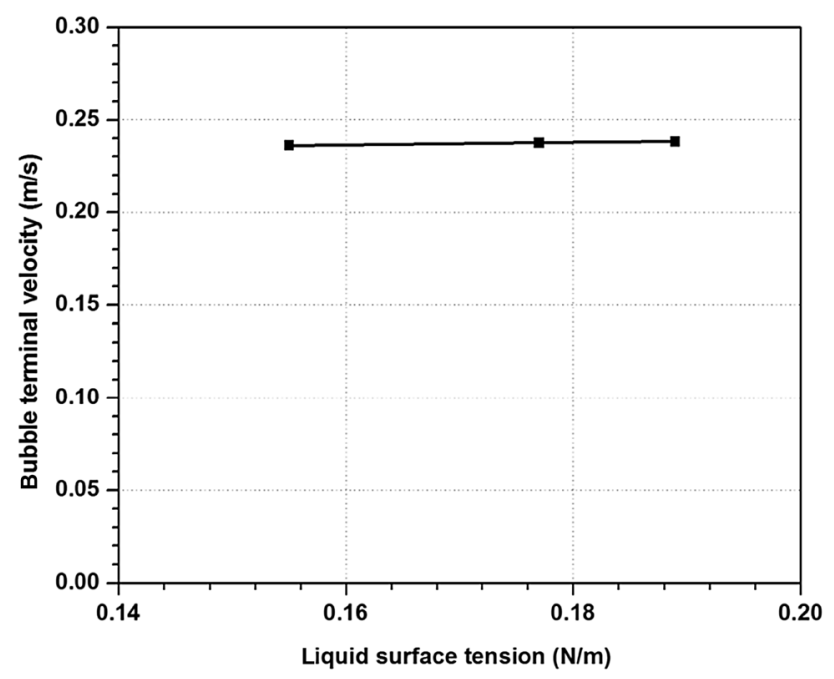

Figure 20. Bubble terminal velocity with liquid surface tension for $20 \mathrm{~mm}$ bubble.

bubble dynamics for $20 \mathrm{~mm}$ size is observed to be similar in liquid sodium and water systems, except for the lower breakup and higher bottom bubble oscillations characteristics in sodium systems due to higher surface tension. Hence, the present study supports the use of water as a

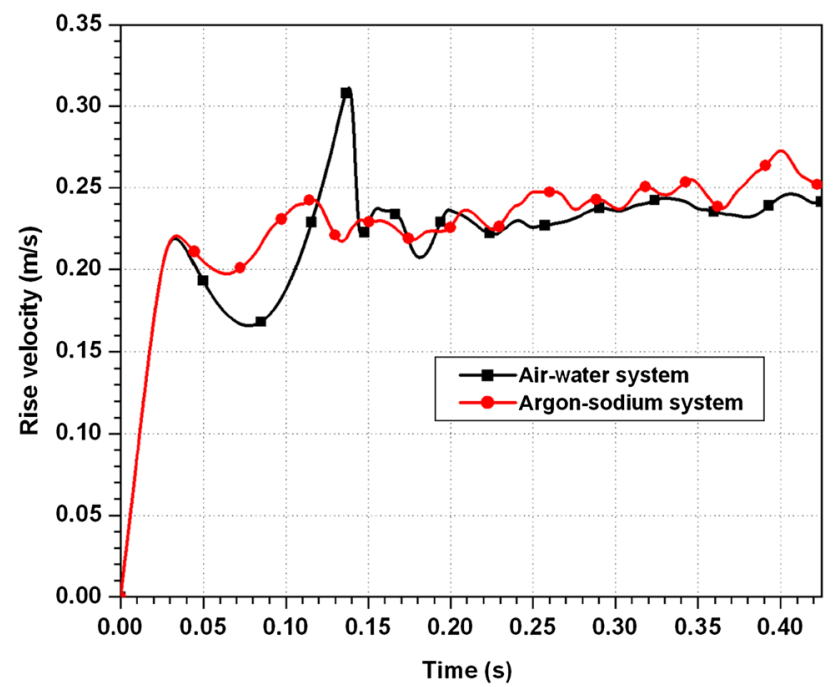

Figure 21. Simulation results of $20 \mathrm{~mm}$ bubble for instantaneous rising velocity of bubble.

simulant for sodium systems in bubble dynamic experiments as suggested in literature for SFR source term studies. The study is very useful and forms an intermediate step towards the development of an OpenFOAM based computational framework to analyze heat and mass transfer

Table 9. Fluid properties of $20 \mathrm{~mm}$ bubble for air-water and argon-sodium system.

\begin{tabular}{|c|c|c|c|c|c|c|c|c|}
\hline Case & $\rho_{1}\left(\mathrm{~kg} / \mathrm{m}^{3}\right)$ & $\rho_{2}\left(\mathrm{~kg} / \mathrm{m}^{3}\right)$ & $\mu_{I}$ (Pa.s) & $\mu_{2}$ (Pa.s) & $\sigma(\mathrm{N} / \mathrm{m})$ & Mo & $\operatorname{Re}$ & Eo \\
\hline Air-water $(T=303 \mathrm{~K})$ & 995 & 1.2 & $8.0 \times 10^{-4}$ & $1.8 \times 10^{-5}$ & 0.07 & $1.1 \times 10^{-11}$ & 10953 & 54.9 \\
\hline Argon-sodium $(T=473 \mathrm{~K})$ & 904 & 1.0 & $4.5 \times 10^{-4}$ & $3.2 \times 10^{-5}$ & 0.19 & $6.7 \times 10^{-14}$ & 17714 & 18.8 \\
\hline
\end{tabular}




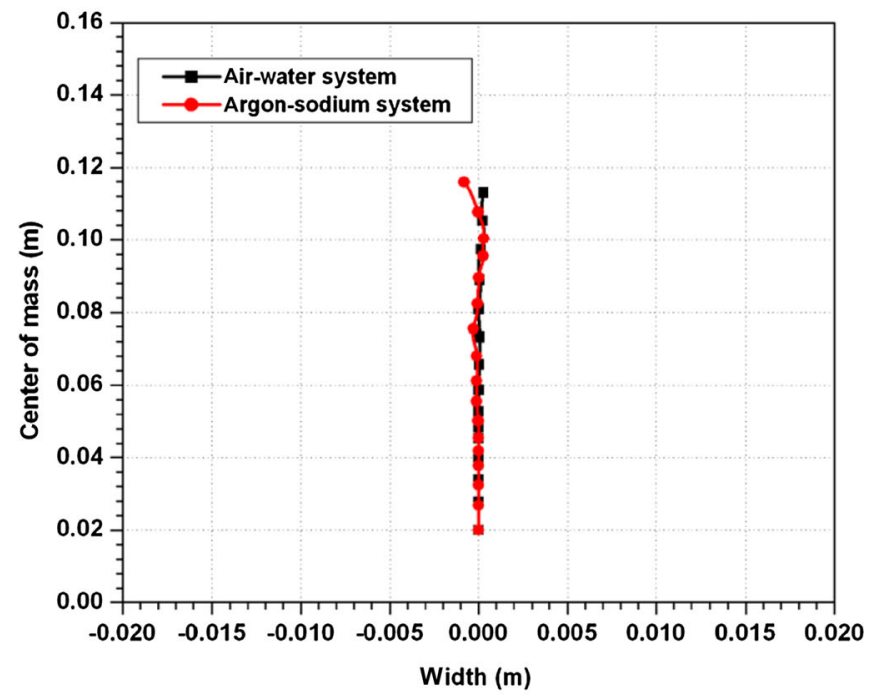

(a)

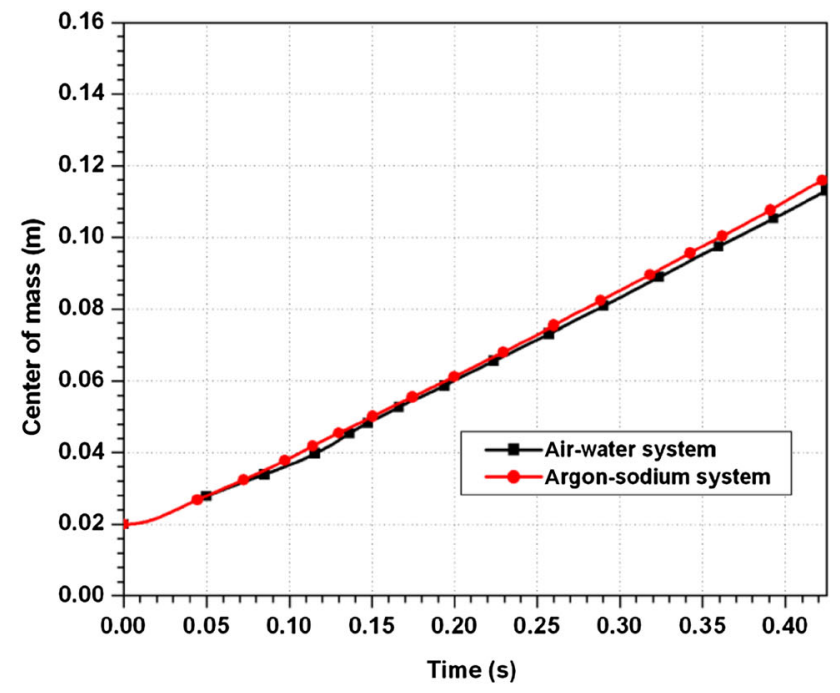

(b)

Figure 22. (a) Lateral position of center of mass. (b) Axial position of center of mass with time for $20 \mathrm{~mm}$ bubble.

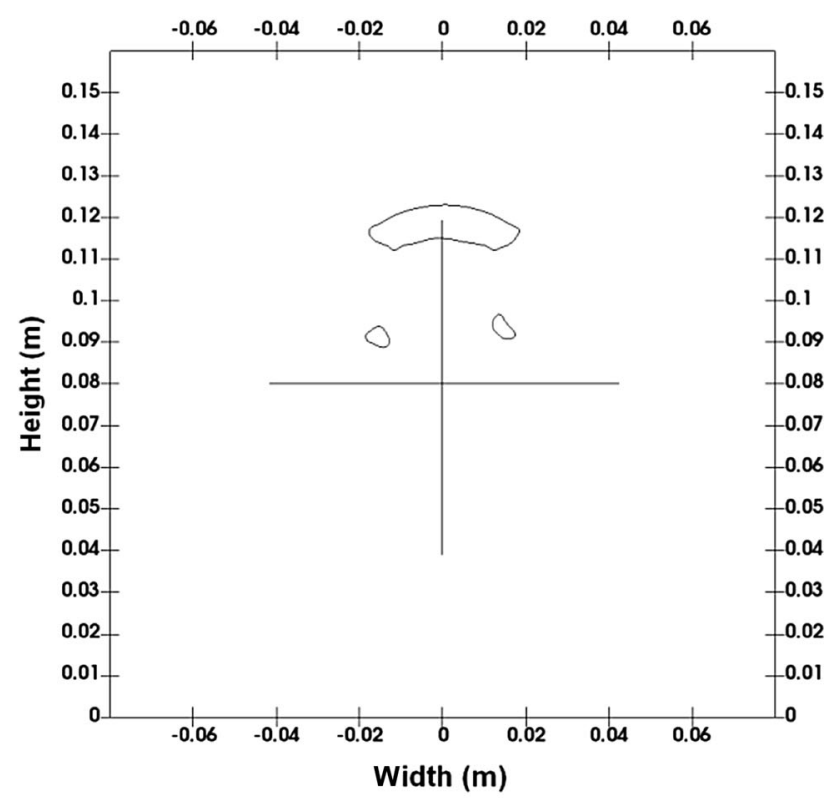

(a)

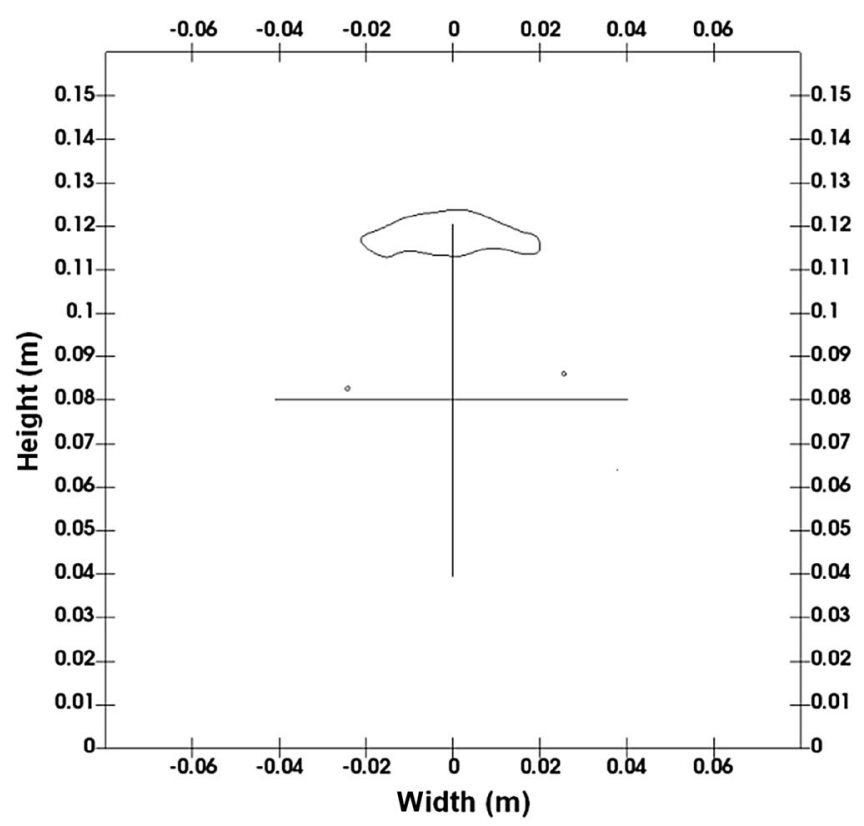

(b)

Figure 23. Bubble contour for $20 \mathrm{~mm}$ at $t=0.425 \mathrm{~s}$ for (a) air-water system, (b) argon-sodium system.

from single bubble rising in liquid sodium pool for reactor safety studies.

\section{References}

[1] Henry R E, Grolmes M A and Fauske H K 1971 Pressurepulse propagation in two-phase one- and two- component mixtures. $A N L-7792$. Argonne National Laboratory Illinois
[2] Pradeep A, Sharma A K 2018 Semiempirical model for wet scrubbing of bubble rising in liquid pool of sodium-cooled fast reactor. Nucl. Eng. Technol. 50: 849-853

[3] Puthiyavinayagam P 2015 Progress in Fast Reactor Programme of India: April 2014-March 2015. In: Proceedings of the 48th Annual Meeting of TWGFR, IAEA IPPE. Obninsk. Russia

[4] Clift R, Grace J R and Weber M E 1978 Bubbles, drops and particles. New York: Academic Press, pp.183-216

[5] Shevchenko N, Boden S, Eckert S, Borin D, Heinze M and Odenbach S 2013 Application of X-ray radioscopic methods 
for characterization of two-phase phenomena and solidification processes in metallic melts. The Euro. Phys. J. Special Topics 220: 63-77

[6] Han Z and Holappa L 2003 Bubble bursting phenomenon in gas/metal/slag systems. Metallurgical and Materials Trans. B. 34B: 525-532

[7] Guézennec A G et al 2004 Dust formation by bubble-burst phenomenon at the surface of a liquid steel bath. Iron and Steel Institute of Japan Int. 44(8): 1328-1333

[8] Wang X 2015 Numerical simulation of two-dimensional bubble dynamics and evaporation. PhD Thesis. KU Leuven Arenberg doctoral school, Belgium

[9] Wang Z and Tong A Y 2008 Deformation and oscillations of a single gas bubble rising in a narrow vertical tube. Int. J. Therm. Sci. 47: 221-228

[10] Raees F, Heul D R V D and Vuik C 2011 Evaluation of the interface-capturing algorithm of OpenFOAM for the simulation of incompressible immiscible two-phase flow. Report. Department of Applied Mathematical Analysis. Delft University of Technology, Netherlands

[11] Klostermann J, Schaake K and Schwarze R 2013 Numerical simulation of a single rising bubble by VOF with surface compression. Int. J. Num. Methods in Fluids 71: 960-982

[12] Xu Y, Ersson M and Jönsson P 2015 Numerical simulation of single argon bubble rising in molten metal under a laminar flow. Steel Research Int. 86(11): 1289-1297

[13] Pradeep A et al 2015 Numerical simulation of gas bubble rising in a liquid pool of SFR. Indo-UK workshop on Modelling and Simulation of Safety and Materials for Nuclear Applications MSMNA-2015. Anupuram. Tamilnadu, India

[14] Pradeep A et al 2016 Numerical modelling of inert gas bubble rising in liquid metal pool. Proceedings of the 6th International and 43rd National Conference on Fluid Mechanics and Fluid Power MNNITA. Allahabad. India

[15] Verma A, Babu R and Das M K 2017 Modelling of a single bubble rising in a liquid column. In: Proceedings of the 5th International and 41st National Conference on FMFP 2014. A K Saha, et al Editors, 2017, Springer India, New Delhi, pp. 1059-1068

[16] Miyahara S and Sagawa N 1996 Iodine mass transfer from xenon-iodine mixed gas bubble to liquid sodium pool, (II) development of analytical model. J. Nucl. Sci. Technol. 33(3): 220-228
[17] Dickinson D R and Nunamaker F H 1975 LMFBR source term iodine attenuation test of bubble breakup/coalescence in LMFBR outlet plenum following large fission gas release. No. HEDL-TC-537. Hanford Engineering Development Lab. Richland. Wash. USA

[18] Quarterly Technical Progress Report, Nuclear Safety, Characterization of Sodium Fires and Fast Reactor Fission Products, January-March 1976 AI-ERDA-13172. Atomics International

[19] Umbel M 2011 Containment Source Terms for SodiumCooled Fast Reactor Accidents. Master's Thesis. The Ohio State University, USA

[20] Damián S M 2012 Description and utilization of interFoam multiphase solver. Final Work. Computational Fluid Dynamics http://infofich.unl.edu.ar/upload/3be0e160650265 27477b4b948c4caa7523c8ea52.pdf

[21] Greenshields C J 2016 OpenFOAM user guide

[22] Hirt C W and Nichols B D 1981 Volume of fluid (VOF) method for the dynamics of free boundaries. J. Comp. Phys. 39: 201-225

[23] Brackbill J U, Kothe D B and Zemach C 1992 A continuum method for modeling surface tension. J. Comp. Phys. 100: $335-354$

[24] Van Leer B 1979 Towards the ultimate conservative difference scheme. V. A second-order sequel to Godunov's method. J. Comp. Phys. 32: 101-136

[25] Herreras N and Izarra J 2013 Two-Phase Pipe Flow Simulations with OpenFOAM. Master's thesis. Norwegian University of Science and Technology, Norway

[26] Rusten E S A 2013 Numerical study of the droplet-interface dynamic related to liquid-liquid separators. Master's thesis. Department of Physics. Norwegian University of Science and Technology, Norway

[27] Hysing S, Turek S, Kuzmin D, Parolini N, Burman E, Ganesan S and Tobiska L 2009 Quantitative benchmark computations of two-dimensional bubble dynamics. Int. J. Num. Methods in Fluids 60: 1259-1288

[28] http://www.featflow.de/en/benchmarks/cfdbenchmarking/ bubble/bubble_reference.html

[29] Krishna R and Baten J M V 1999 Rise characteristics of gas bubbles in a 2D rectangular column: VOF simulations vs experiments. Int. Comm. Heat Mass Transf. 26(7): 965-974

[30] Levich V G 1962 Physiochemical Hydrodynamics. Englewood Cliffs. New Jersey: Prentice Hall 